Article

\title{
Increasing Incidence and Shifting Epidemiology of Candidemia in Greece: Results from the First Nationwide 10-Year Survey
}

\author{
Vasiliki Mamali ${ }^{1}$, Maria Siopi ${ }^{2}{ }^{\circledR}$, Stefanos Charpantidis ${ }^{3}$, George Samonis ${ }^{4}$, Athanasios Tsakris ${ }^{5}{ }^{\oplus}$, \\ Georgia Vrioni ${ }^{5, *}$ (D) and on behalf of the Candi-Candi Network ${ }^{+}$
}

check for

updates

Citation: Mamali, V.; Siopi, M.;

Charpantidis, S.; Samonis, G.;

Tsakris, A.; Vrioni, G.; on behalf of the Candi-Candi Network. Increasing Incidence and Shifting Epidemiology of Candidemia in Greece: Results from the First Nationwide 10-Year Survey. J. Fungi 2022, 8, 116. https://doi.org/10.3390/jof8020116

Academic Editor: Damian J. Krysan

Received: 23 December 2021

Accepted: 23 January 2022

Published: 26 January 2022

Publisher's Note: MDPI stays neutral with regard to jurisdictional claims in published maps and institutional affiliations.

Copyright: (C) 2022 by the authors. Licensee MDPI, Basel, Switzerland. This article is an open access article distributed under the terms and conditions of the Creative Commons Attribution (CC BY) license (https:// creativecommons.org/licenses/by/ $4.0 /)$.
1 Department of Microbiology, Tzaneio General Hospital, 18536 Piraeus, Greece mamalivasiliki@outlook.com.gr

2 Clinical Microbiology Laboratory, "Attikon” University General Hospital, Medical School, National and Kapodistrian University of Athens, 12462 Athens, Greece; marizasiopi@hotmail.com

3 Department of Microbiology, "Elena Venizelou” Maternity Hospital, 11521 Athens, Greece; steve_kavala2@hotmail.com

4 Department of Internal Medicine, School of Medicine, University of Crete, 71003 Heraklion, Greece; samonis@med.uoa.gr

5 Department of Microbiology, Medical School, National and Kapodistrian University of Athens, 11527 Athens, Greece; atsakris@med.uoa.gr

* Correspondence: gvrioni@med.uoa.gr; Tel.: +30-210-746-2129

$\dagger$ A full list of the Candi-Candi Network is given in the Appendix A.

\begin{abstract}
Globally, candidemia displays geographical variety in terms of epidemiology and incidence. In that respect, a nationwide Greek study was conducted, reporting the epidemiology of Candida bloodstream infections and susceptibility of isolates to antifungal agents providing evidence for empirical treatment. All microbiologically confirmed candidemia cases in patients hospitalized in 28 Greek centres during the period 2009-2018 were recorded. The study evaluated the incidence of infection/100,000 inhabitants, species distribution, and antifungal susceptibilities of isolated strains. Overall, 6057 candidemic episodes occurred during the study period, with 3\% of them being mixed candidemias. The average annual incidence was 5.56/100,000 inhabitants, with significant increase over the years $(p=0.0002)$. C. parapsilosis species complex (SC) was the predominant causative agent $(41 \%)$, followed by C. albicans (37\%), C. glabrata SC (10\%), C. tropicalis (7\%), C. krusei (1\%), and other rare Candida spp. (4\%). C. albicans rates decreased from 2009 to 2018 (48\% to 31\%) in parallel with a doubling incidence of $C$. parapsilosis SC rates $(28 \%$ to $49 \%, p<0.0001)$. Resistance to amphotericin B and flucytosine was not observed. Resistance to fluconazole was detected in $20 \%$ of $C$. parapsilosis SC isolates, with a $4 \%$ of them being pan-azole-resistant. A considerable rising rate of resistance to this agent was observed over the study period $(p<0.0001)$. Echinocandin resistance was found in 3\% of C. glabrata SC isolates, with $70 \%$ of them being pan-echinocandinresistant. Resistance rate to this agent was stable over the study period. This is the first multicentre nationwide study demonstrating an increasing incidence of candidemia in Greece with a species shift toward C. parapsilosis SC. Although the overall antifungal resistance rates remain relatively low, fluconazole-resistant $C$. parapsilosis SC raises concern.
\end{abstract}

Keywords: candidemia; epidemiology; Greece; species distribution; antifungal resistance

\section{Introduction}

Candidemia is among the leading nosocomial bloodstream infections (BSIs) globally, representing the most frequently encountered manifestation of invasive candidiasis. Regardless of the ongoing advances in treatment algorithms and availability of new antifungal agents with improved spectrum and potency, it remains associated with high mortality rates [1,2]. Meanwhile, Candida BSIs contribute towards prolonged hospital stay, imposing a considerable economic burden on the health care systems, since $\$ 157,574$ / patient are 
spent on their management, excluding attributable costs ( $\$ 82,320 /$ patient) [3]. Of note, prompt management of candidemia is crucial to improve clinical outcome, given that delays in time to treatment initiation have been associated with increased mortality $[4,5]$. On these grounds, empirical antifungal therapy with echinocandins, fluconazole, or a lipid formulation of amphotericin B is often prescribed as soon as possible to patients with traditional risk factors for developing the infection, long before definitive identification and susceptibility data become available [6]. Therefore, in-depth understanding and monitoring of temporal local epidemiological and in vitro antifungal susceptibility trends is imperative in terms of guiding informed therapeutic decisions.

The epidemiology of candidemia may change over time, whilst its patterns can present significant geographical, centre-to-centre, and even unit-to-unit variability, due to local factors and practices [2]. Although C. albicans is still considered the main causative pathogen, a progressive shift to non-albicans Candida (NAC) spp. is currently recorded in most parts of the world [2,7]. At the same time, emerging azole and echinocandin resistance among commonly isolated species displays major challenges for therapeutic strategies [2,7], whereas novel pathogenic species with multi-resistance profiles, such as $C$. auris, set a worrisome trend and amplify the call for alertness [8]. Taking into account that each Candida spp. has a unique virulence potential, clinical characteristics, and antifungal susceptibility profile, the evolving epidemiology of Candida BSIs may have different implications regarding their management, thus reinforcing the need for comprehensive regional and local epidemiological surveillance with provision of feedback at regular intervals.

To date, although a plethora of studies have addressed the menace of candidemia worldwide, data on its contemporary prevalence and resistance patterns in Greece are relatively few, while published reports are limited to single-centre studies, small geographical regions, and distinct patient populations [9]. As a consequence, results may not be generalizable regarding all candidemic patients; neither can conclusions be extrapolated regarding other centres as the epidemiology of the infection can be highly institution-specific. Based on these grounds, a nationwide study was conducted to describe the current epidemiological characteristics of Candida BSIs in Greece and the susceptibilities of the causative strains to antifungal agents, and to provide up-to-date evidence for empirical treatment.

\section{Materials and Methods}

Study design. A retrospective, laboratory-based study of patients with candidemia was conducted in 28 Greek hospitals during the period 2009-2018. Namely, in the study were included 26 public hospitals (16 general, 6 university-affiliated, 2 cancer, 1 maternity, and 1 military) and two private, regional, general hospitals. The participating centres were geographically distributed in densely populated metropolitan areas across the country covering all seven Greek regional administrative health authorities [10]: 20 of them located in the Attica region ( $35 \%$ of the country's population), 5 in Northern Greece (Alexandroupolis, Ioannina, Serres and Thessaloniki), 1 in Central Greece (Larissa), 1 in Southern Greece (Patras), and 1 on the island of Crete (Heraklion) (Figure 1). The study was planned and registered as "HSoMM (Hellenic Society of Medical Mycology) Candi-Candi Network: an observational study".

Candidemia was defined as the recovery of Candida spp. from at least one blood culture set during hospitalization. A case was defined as intensive care unit (ICU)-acquired candidemia if it occurred $>48 \mathrm{~h}$ after ICU admission [11]. Subsequent positive blood cultures with the same Candida spp. from a single patient were considered as a new episode if the episodes occurred $>4$ weeks apart, along with the clearance of the prior blood culture and resolution of all clinical features of the infection. Blood cultures yielding different Candida spp., independently of the time interval between the new and the prior positive blood culture, were considered to represent new episodes. Patients with mixed candidemia (MC), identified as the isolation of two different Candida spp. from a single blood culture sample, were included. Medical unit at the onset of infection and mycological findings (species identification and in vitro susceptibility profile of the causative pathogens) 
were retrospectively obtained from individual laboratory records or the microbiological laboratory computerized database of each participating hospital.

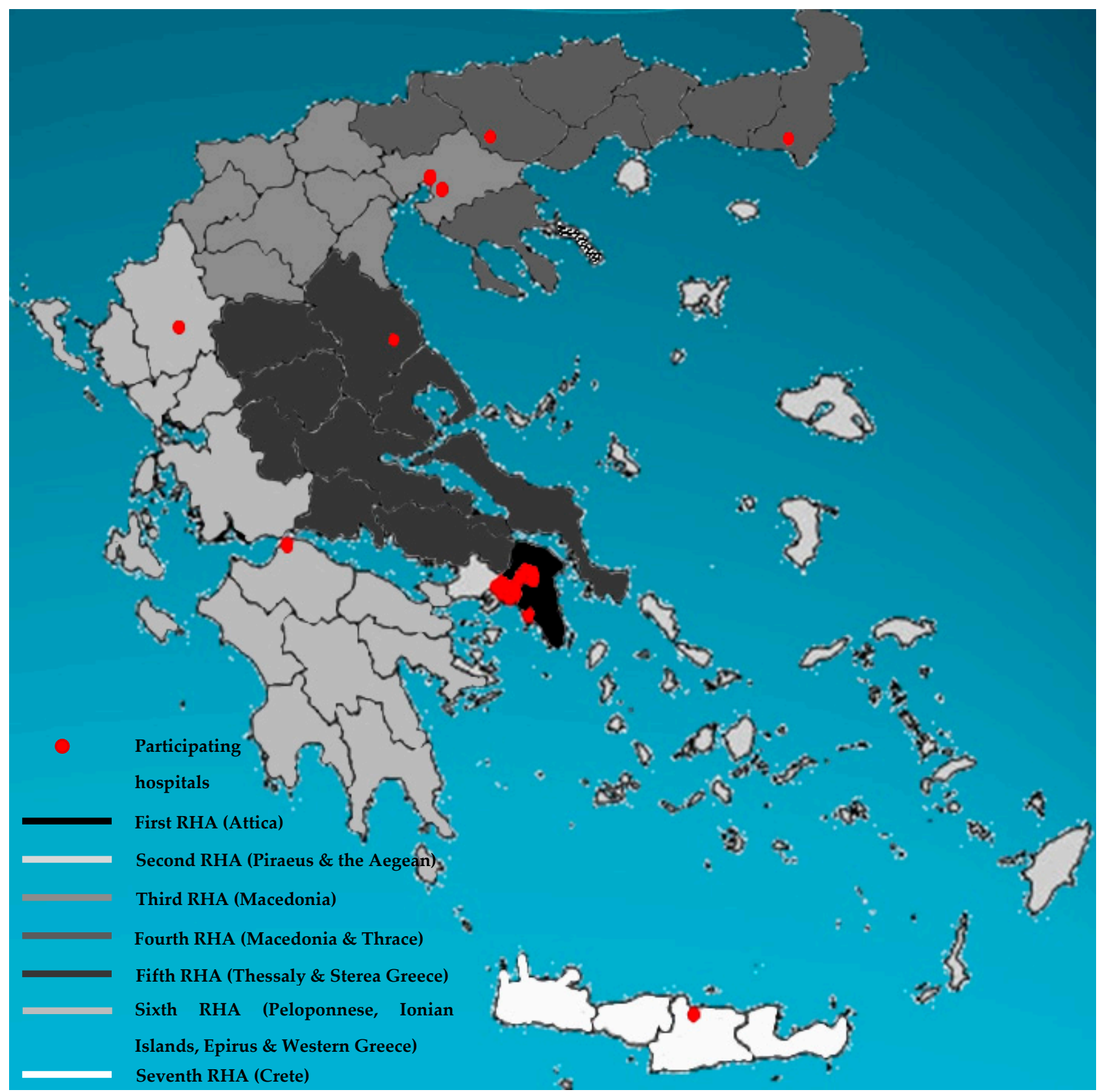

Figure 1. Geographic distribution of the 28 participating hospitals (red dots) across the seven Greek regional health authorities (RHA).

Identification and antifungal susceptibility testing. Fungal isolates were identified to species level as per hospital protocol by germ tube production, colony colour, and morphology on chromogenic agar (4/28 participating centres) and analysis of biochemical pattern using automated systems (Vitek ${ }^{\circledR} 2$ (BioMeriéux, Marcy l'Etoile, France), BD Phoenix ${ }^{\mathrm{TM}}$ (BD, Sparks, MD, USA)) or commercially available kits (Auxacolor (Bio-Rad, Hercules, CA, USA), MicroScan Rapid Yeast Identification (Beckman Coulter, Brea, CA, USA), API 20C AUX and ID 32C (BioMeriéux, Marcy l'Etoile, France)).

In vitro susceptibility was determined as per hospital protocol using the automated susceptibility testing system Vitek ${ }^{\circledR} 2$ (BioMeriéux, Marcy l'Etoile, France), gradient concentration strips (Etest (BioMeriéux, Marcy l'Etoile, France), MTS (Liofilchem, Roseto degli 
Abruzzi, Italy)), the colorimetric assay Sensititre YeastOne (SYO; Thermo Fisher Scientific, Cleveland, $\mathrm{OH}, \mathrm{USA}$ ), or the broth microdilution reference method following the European Committee on Antimicrobial Susceptibility Testing (EUCAST) guidelines [12,13]. Vitek $^{\circledR} 2$ [14-16], Etest/MTS [17], and SYO [16,18] have been shown to give comparable results to those obtained by the Clinical and Laboratory Standards Institute (CLSI) procedure for antifungal susceptibility testing of yeasts. Thus, for the categorization of the isolates, the M60 CLSI species-specific clinical breakpoints were applied [19] and in the absence of those method-specific (CLSI (for data obtained by Vitek ${ }^{\circledR}$ 2) [20], Etest [21-23], or SYO $[22,24,25])$, epidemiological cut-off values (ECVs) were used to differentiate wild type (WT) and non-WT phenotypes.

Statistical analysis. The incidence of candidemia was expressed as the ratio of Candida BSI episodes per 100,000 inhabitants, based on the annual population data extracted from the World Bank subnational population database [26], whereas its trends over time were evaluated by linear regression analysis and ANOVA, followed by post-test for linear trend. Medians and interquartile ranges (IQR) were calculated for continuous variables, while numbers and percentages were calculated for categorical parameters. Categorical variables were compared by Pearson's chi-square test. In any case, a two-tailed $p$ value of $<0.05$ was considered to reveal a statistically significant difference. All data were analysed using the statistics software package GraphPad Prism, version 8.0, for Windows (GraphPad Software, San Diego, CA, USA).

\section{Results}

Candidemia incidence. Over the 10-year study period, a total of 6057 Candida BSIs were recorded, whereas no patient had separate episodes with distinct Candida spp. The median (range, IQR) number of cases reported per year was $639(373-811,214)$. The distribution of episodes in age categories was $132(2 \%)$ in neonates, $69(1 \%)$ in children, and $5856(97 \%)$ in adults. The overall incidence of candidemia was 5.56/100,000 inhabitants with a significant increase over the years, particularly between 2009-2011, 2012-2014, and 2015-2018 (3.75, 5.83, and 7.01/100,000 inhabitants, respectively; $p=0.0002)$. The highest number of cases was determined in 2017, with a ratio of 7.54/100,000 inhabitants, while the lower was in 2009 with 3.36/100,000 inhabitants (Figure 2). Almost half (2665/6057; $44 \%$ ) of the episodes occurred in patients admitted in internal medicine wards (IMWs), 1999/6057 (33\%) in ICUs (1827/1999; 91\% in adult, 40/1999; $\%$ in paediatric, 132/1999; $7 \%$ in neonatal), and 1393/6057 (23\%) in surgery wards (SWs). The median (range, IQR) number of candidemias reported per year was 284 (219-306, 87), 209 (169-227, 58), and 146 (111-160, 49) in IMWs, ICUs, and SWs, respectively.

Candida species distribution. A total of 6239 non-duplicate Candida spp. isolates were recorded, 37\% (2333/6239) were C. albicans and 63\% (3906/6239) were NAC spp. $(p<0.0001)$. Of note, C. albicans rates decreased from 2009 to $2018(48 \%$ to $31 \%)$ in parallel with a doubling of $C$. parapsilosis species complex (SC) rates ( $28 \%$ to $49 \%$; $p<0.0001)$ (Figure 2). No significant change was observed in the proportions of other Candida spp. Overall, C. parapsilosis SC accounted for the majority of isolates $(n=2582 ; 41 \%)$ followed by $C$. albicans $(n=2333 ; 37 \%)$, comprising $78 \%$ of all Candida BSIs. Other commonly encountered Candida spp. included C. glabrata SC $(n=594 ; 10 \%)$, C. tropicalis $(n=423$; $7 \%)$, and $C$. krusei $(n=86 ; 1 \%)$. Other species, such as $C$. lusitaniae $(n=73), C$. famata $(n=36)$, C. guilliermondii SC $(n=28), C$. dubliniensis $(n=22)$, C. sake $(n=16)$, C. kefyr $(n=12)$, C. lipolytica $(n=8)$, C. pelliculosa and C. rugosa (each $n=6)$, C. ciferrii and C. zeylanoides (each $n=3$ ), C. norvegensis and C. sphaerica (each $n=2$ ), C. globosa, C. intermedia, C. pulcherrima, and $C$. utilis (each $n=1)$, were relatively rare $(n=221 ; 4 \%)$. Depending on the year, the percentage of isolated species varied from $31 \%$ to $48 \%$ for C. albicans, $28 \%$ to $49 \%$ for C. parapsilosis SC, $8 \%$ to $12 \%$ for C. glabrata SC, $5 \%$ to $11 \%$ for C. tropicalis, $1 \%$ to $3 \%$ for C. krusei, and 3\% to $8 \%$ for other Candida spp. (Figure 2). 


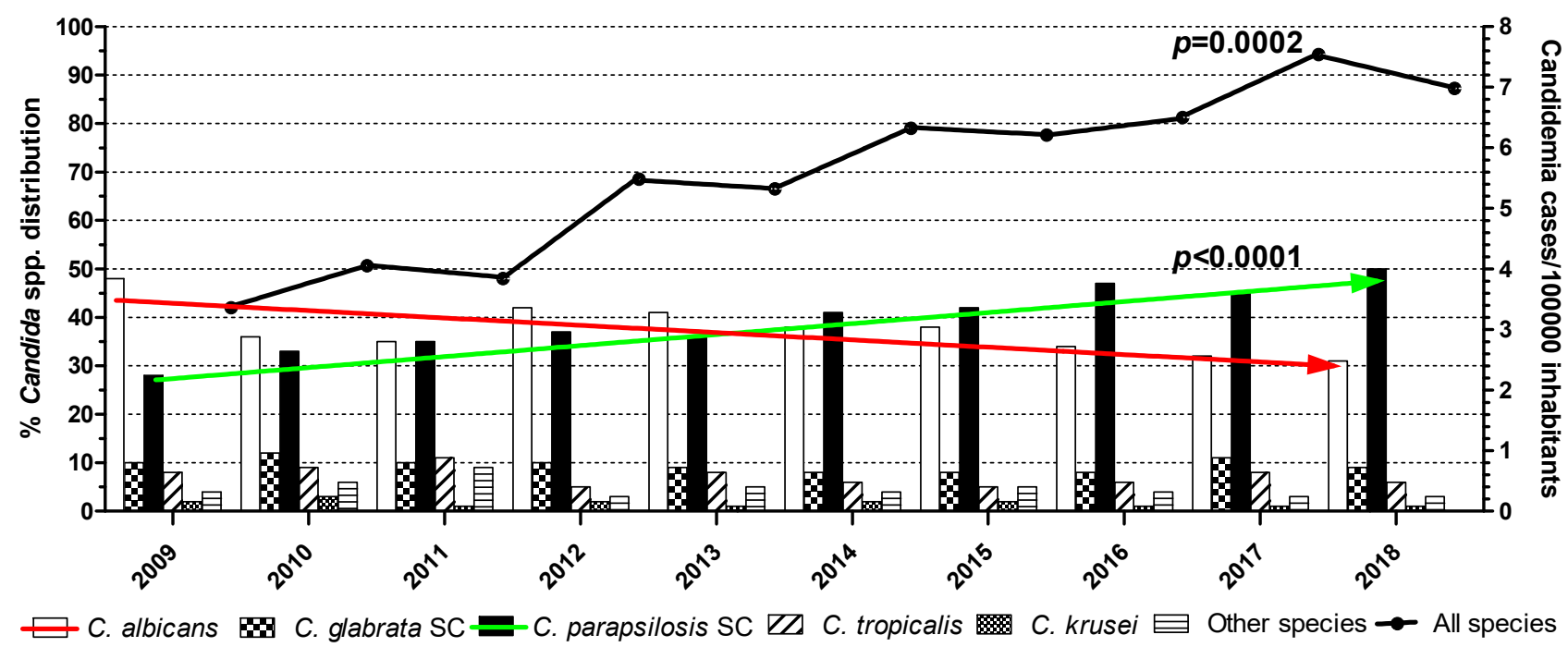

Figure 2. Species distribution of Candida bloodstream isolates and temporal changes in candidemic episodes per 100,000 inhabitants. Statistically significant differences between the isolation rates of C. albicans (red falling arrow) and C. parapsilosis species complex (SC; green rising arrow) $(p<0.0001)$ and in the incidence of candidemia $(p=0.0002)$ were recorded over the years.

Temporal distributions of Candida spp. in different hospital wards are shown in Figure 3. The proportion of C. albicans versus NAC spp. isolates differed significantly in all admission wards at the time of diagnosis (IMWs 39\% versus $61 \%$, SWs $38 \%$ versus $62 \%$ and ICUs $32 \%$ versus $68 \%$, respectively; $p<0.0001$ ). A higher proportional increase of C. parapsilosis SC isolation rate was recorded in wards, from $25 \%$ and $18 \%$ in 2009 to $44 \%$ and $50 \%$ in 2018 in IMWs $(p<0.0001)$ and SWs $(p=0.0003)$, respectively, than in the ICUs, from $42 \%$ in 2009 to $59 \%$ in 2018 ( $p=0.002)$. Distinct unit-related patterns of species distribution were not observed $(p=0.96)$. C. parapsilosis SC was the most frequently seen species in adult ICUs $(48 \%)$ and almost equally distributed with $C$. albicans in IMWs (37\% versus $39 \%$, respectively) and SWs (39\% versus 38\%, respectively), while almost half $(97 / 201 ; 48 \%)$ of the neonatal/paediatric patients were infected with C. parapsilosis SC isolates.

Out of 4/28 participating hospitals using chromogenic agar for Candida as an additional primary isolation medium, candidemia with two distinct Candida spp. was determined in 24/795 (3\%) cases, with C. albicans being the species most frequently isolated in combination with others $(17 / 24 ; 71 \%)$. In particular, 13 patients $(54 \%)$ presented with C. albicans and C. parapsilosis SC, $3(13 \%)$ with C. glabrata SC and C. parapsilosis SC, $2(9 \%)$ with C. albicans and C. glabrata SC, $1(4 \%)$ with C. parapsilosis SC and C. tropicalis, $1(4 \%)$ with C. albicans and C. krusei, $1(4 \%)$ with C. albicans and C. lusitaniae, $1(4 \%)$ with C. albicans and C. kefyr, $1(4 \%)$ with C. parapsilosis SC and C. kefyr, and $1(4 \%)$ with C. parapsilosis SC and $C$. sake. The majority of the MC episodes occurred in patients hospitalized in IMWs $(17 / 24 ; 71 \%)$, while $5 / 24(21 \%)$ occurred in SWs and $2 / 24(8 \%)$ in the ICUs.

Antifungal susceptibility profile. The results of in vitro susceptibilities to antifungal agents were available for a subset of Candida bloodstream isolates, depending on the method used for susceptibility testing. Namely, 3615/6239 (58\%) strains were tested using Vitek ${ }^{\circledR}$, and thus amphotericin $\mathrm{B}(\mathrm{AMB})$, flucytosine (5FC), micafungin (MFG), caspofungin (CAS), voriconazole (VRC) and fluconazole (FLC) minimum inhibition concentrations (MICs) were available. MIC values of these antifungals as well as anidulafungin (AFG), posaconazole (POS) and itraconazole (ITC) were obtained for 914/6239 (15\%) and 469/6239 (7\%) isolates by Etest/MTS and SYO, respectively. AMB, echinocandins and azoles (except for ITC) EUCAST MICs were determined for 51/6239 (1\%) isolates. For the rest 1190/6239 (19\%) isolates, susceptibility data were not available. 
The in vitro susceptibility results for each Candida spp. to antifungals are summarized in Table 1. Overall, the majority of isolates were susceptible/WT to the drugs tested. No resistance to AMB and 5FC was found.

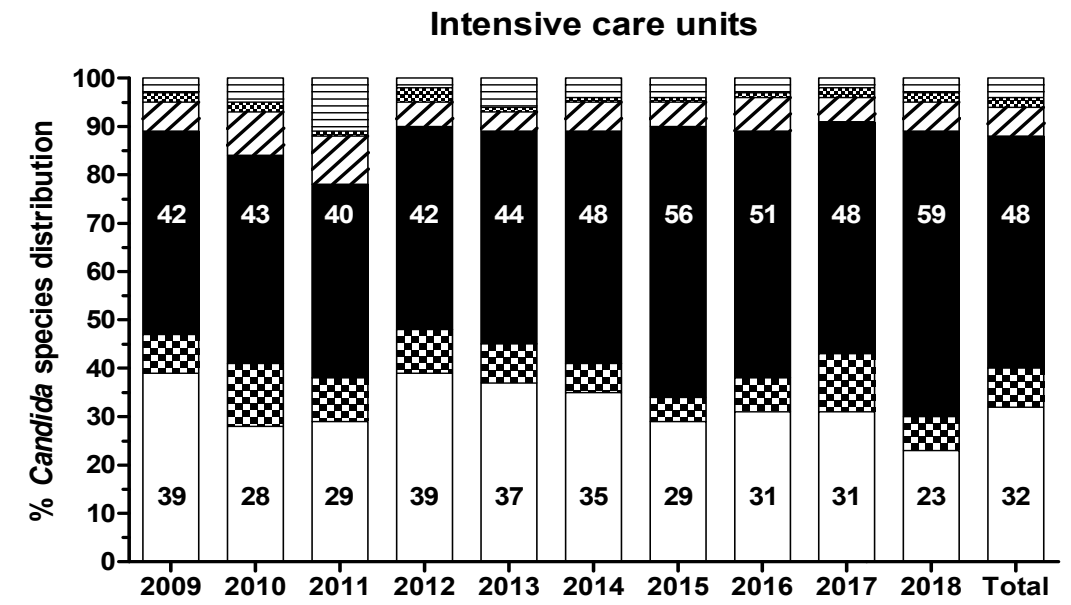

Internal medicine wards

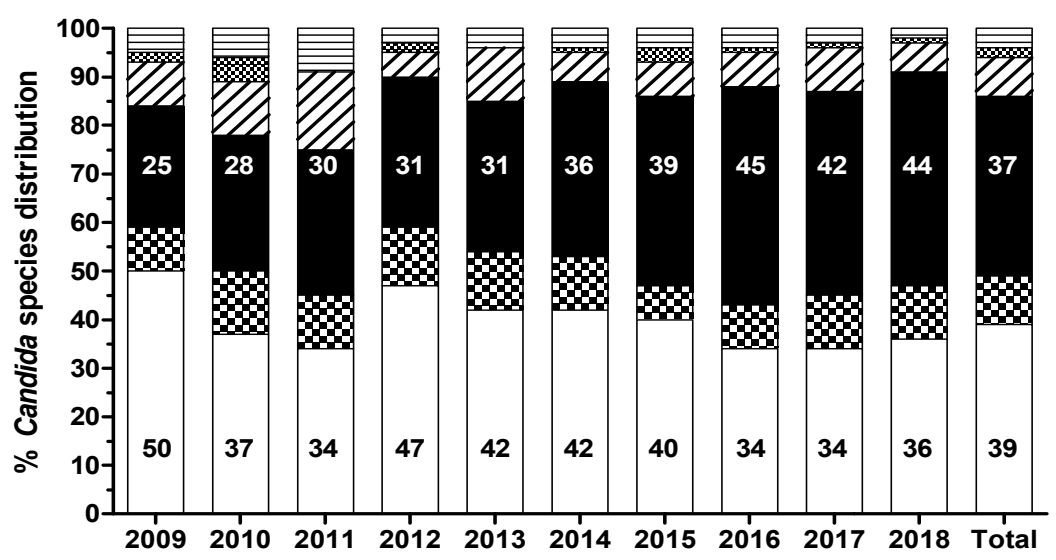

Surgical wards

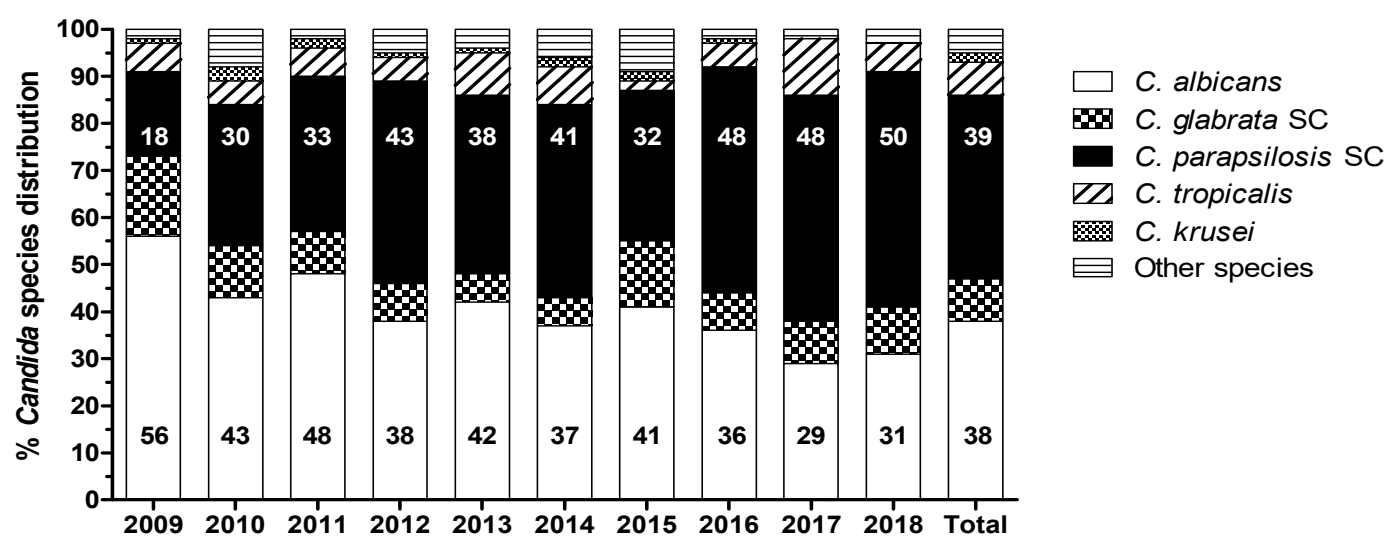

Figure 3. Trends in the ward-wise distribution of Candida spp. over the years. Statistically significant differences between $C$. albicans and non-albicans Candida spp. were recorded in all medical units $(p<0.0001)$, mainly due to the notable increases in the frequency of $C$. parapsilosis species complex (SC) isolation. 
Table 1. In vitro susceptibility profile of Candida bloodstream isolates collected during 2009-2018 to nine antifungals. Susceptibility testing was performed as per hospital protocol.

\begin{tabular}{|c|c|c|c|c|c|c|}
\hline \multirow{2}{*}{$\begin{array}{c}\text { Candida spp. } \\
\text { and Antifungal } \\
\text { Agent }\end{array}$} & \multirow{2}{*}{$\begin{array}{l}\text { No of } \\
\text { Isolates }\end{array}$} & \multicolumn{3}{|c|}{ Clinical Breakpoints * } & \multicolumn{2}{|c|}{ ECVs/ECOFFs * } \\
\hline & & $\mathrm{S}$ & I/SDD & $\mathbf{R}$ & WT & Non-WT \\
\hline & & No $(\%)$ & No (\%) & No $(\%)$ & No (\%) & No $(\%)$ \\
\hline C. albicans & & & & & & \\
\hline Anidulafungin & 724 & $724(100)$ & $0(0)$ & $0(0)$ & - & - \\
\hline Caspofungin & 1883 & 1794 (95) & $24(1)$ & $50(3)$ & $15(1)$ & - \\
\hline Micafungin & 1883 & 1846 (98) & 25 (1) & $12(1)$ & - & - \\
\hline Flucytosine & 1868 & - & - & - & $1868(100)$ & $0(0)$ \\
\hline Fluconazole & 1883 & 1793 (95) & $41(2)$ & $49(3)$ & - & - \\
\hline Itraconazole & 709 & - & - & - & $681(96)$ & $28(4)$ \\
\hline Posaconazole & 724 & $15(2)$ & - & - & $690(95)$ & $19(3)$ \\
\hline Voriconazole & 1883 & $1732(92)$ & $94(5)$ & $57(3)$ & - & - \\
\hline Amphotericin B & 1883 & - & - & - & $1883(100)$ & $0(0)$ \\
\hline C. parapsilosis SC & & & & & & \\
\hline Anidulafungin & 396 & $396(100)$ & $0(0)$ & $0(0)$ & - & - \\
\hline Caspofungin & 2216 & $2216(100)$ & $0(0)$ & $0(0)$ & - & - \\
\hline Micafungin & 2216 & $2216(100)$ & $0(0)$ & $0(0)$ & - & - \\
\hline Flucytosine & 2189 & - & por & - & 2189 (100) & $0(0)$ \\
\hline Fluconazole & 2216 & $1717(78)$ & $58(2)$ & $441(20)$ & - & - \\
\hline Itraconazole & 369 & - & - & - & $342(93)$ & $27(7)$ \\
\hline Posaconazole & 369 & - & - & - & 376 (95) & $20(5)$ \\
\hline Voriconazole & 2216 & 2027 (92) & $163(7)$ & $26(1)$ & - & - \\
\hline $\begin{array}{l}\text { Amphotericin B } \\
\text { C. glabrata SC }\end{array}$ & 2216 & - & - & - & $2216(100)$ & $0(0)$ \\
\hline Anidulafungin & 203 & $196(97)$ & $0(0)$ & $7(3)$ & - & - \\
\hline Caspofungin & 500 & 486 (97) & $5(1)$ & $9(2)$ & - & - \\
\hline Micafungin & 500 & 485 (97) & $3(1)$ & $12(2)$ & - & - \\
\hline Flucytosine & 500 & - & - & - & $500(100)$ & $0(0)$ \\
\hline Fluconazole & 500 & & 477 (95) & $23(5)$ & - & - \\
\hline Itraconazole & 203 & - & - & - & $188(93)$ & $15(7)$ \\
\hline Posaconazole & 203 & - & - & - & 179 (88) & 24 (12) \\
\hline Voriconazole & 500 & - & - & - & $470(94)$ & $30(6)$ \\
\hline $\begin{array}{c}\text { Amphotericin B } \\
\text { C. tropicalis }\end{array}$ & 500 & - & - & - & $500(100)$ & $0(0)$ \\
\hline Anidulafungin & 75 & 75 (100) & $0(0)$ & $0(0)$ & - & - \\
\hline Caspofungin & 373 & $366(98)$ & $0(0)$ & $7(2)$ & - & - \\
\hline Micafungin & 373 & 370 (99) & $0(0)$ & $3(1)$ & - & - \\
\hline Flucytosine & 373 & - & & - & $373(100)$ & $0(0)$ \\
\hline Fluconazole & 373 & $322(86)$ & $28(8)$ & $23(6)$ & - & - \\
\hline Itraconazole & 75 & - & - & - & 75 (100) & $0(0)$ \\
\hline Posaconazole & 75 & - & - & - & $75(100)$ & $0(0)$ \\
\hline Voriconazole & 373 & $330(88)$ & $38(10)$ & $5(1)$ & - & - \\
\hline $\begin{array}{l}\text { Amphotericin B } \\
\text { C. krusei }\end{array}$ & 373 & - & - & - & $373(100)$ & $0(0)$ \\
\hline Anidulafungin & 33 & $33(100)$ & $0(0)$ & $0(0)$ & - & - \\
\hline Caspofungin & 77 & $74(96)$ & $1(1)$ & $2(3)$ & - & - \\
\hline Micafungin & 77 & 77 (100) & $0(0)$ & $0(0)$ & - & - \\
\hline Flucytosine & 77 & - & - & - & 77 (100) & $0(0)$ \\
\hline Fluconazole & 77 & - & - & - & 77 (100) & $0(0)$ \\
\hline Itraconazole & 33 & - & - & - & $33(100)$ & $0(0)$ \\
\hline Posaconazole & 33 & - & - & - & $33(100)$ & $0(0)$ \\
\hline Voriconazole & 77 & 77 (100) & $0(0)$ & $0(0)$ & - & - \\
\hline $\begin{array}{c}\text { Amphotericin B } \\
\text { Total }\end{array}$ & 77 & - & & - & $77(100)$ & $0(0)$ \\
\hline Anidulafungin & 1431 & 1424 (99.5) & $0(0)$ & $7(0.5)$ & & \\
\hline Caspofungin & 5049 & 4928 (97.6) & $38(0.8)$ & $68(1.3)$ & $15(0.3)$ & \\
\hline Micafungin & 5049 & 4981 (98.7) & $41(0.8)$ & $27(0.5)$ & & \\
\hline Flucytosine & 5007 & & & & 5007 (100) & $0(0)$ \\
\hline Fluconazole & 5049 & 3832 (75.9) & 604 (12) & $536(10.6)$ & $77(1.5)$ & \\
\hline Itraconazole & 1389 & & & & $1319(95)$ & $70(5)$ \\
\hline Posaconazole & 1431 & $15(1)$ & & & $1353(94.6)$ & $63(4.4)$ \\
\hline Voriconazole & 5049 & 4166 (82.6) & $295(5.8)$ & $88(1.7)$ & $470(9.3)$ & $30(0.6)$ \\
\hline Amphotericin B & 5049 & & & & 5049 (100) & $0(0)$ \\
\hline
\end{tabular}

Abbreviations: SC: species complex, ECVs/ECOFFs: epidemiological cut-off values, S: susceptible, I: intermediate, SDD: susceptible-dose dependent, R: resistant, WT: wild type. * CLSI [19]/EUCAST [13] clinical breakpoints and method-specific ECVs/ECOFFs (CLSI [20], EUCAST [13], Etest [21-23], Sensititre [22,24,25]) were used.

(i). Azoles. For ITC and POS, resistant/non-WT strains were observed among C. albicans (4\% and 3\%, respectively), C. parapsilosis SC (7\% and 5\%, respectively), and C. glabrata SC ( $7 \%$ and $12 \%$, respectively). Interestingly, a significant proportion of the ITC resistant/non-WT isolates, all recovered from IMWs and SWs patients were panazole-resistant/non-WT $(54 \%, 41 \%$, and $47 \%$ of C. albicans, C. parapsilosis SC, and 
C. glabrata SC, respectively). VRC-resistant/non-WT phenotypes were identified among strains of C. albicans (3\%), C. parapsilosis SC (1\%), C. glabrata SC $(6 \%)$, and C. tropicalis (1\%), while $7 \%$ and $10 \%$ of C. parapsilosis SC and C. tropicalis isolates, respectively, displayed elevated VRC MICs $(0.25-0.5 \mathrm{mg} / \mathrm{L})$, categorizing them as intermediate. Worryingly, reduced susceptibility to FLC was mostly seen. In particular, $3 \%$ of C. albicans (18\% pan-azole-resistant/non-WT), 20\% of C. parapsilosis SC, 5\% of C. glabrata SC (3\% pan-azole-resistant/non-WT), and 6\% of C. tropicalis isolates were FLC-resistant, whereas $2 \%$ of $C$. albicans as well as C. parapsilosis SC and $8 \%$ of C. tropicalis isolates were categorized as intermediate. The FLC-resistant C. parapsilosis SC isolates were found in all units (48\% in ICUs, 34\% in IMWs and 18\% in SWs) of the participating hospitals, presenting the $32 \%, 21 \%$, and $20 \%$ of C. parapsilosis SC isolates recovered from candidemic patients admitted to ICUs, IMWs, and SWs, respectively. Alarmingly, their isolation rate was steadily rising throughout the study period: from 1\% during 2009-2011 to 14\% between 2012-2014 and further to 27\% during 2015-2018 $(p<0.0001)$ (Figure 4). Moreover, they have shown different susceptibility profiles to other azoles; $3 \%$ were pan-azole-resistant/non-WT isolates, whilst those with the highest MICs for FLC ( $\geq 32 \mathrm{mg} / \mathrm{L})$ were also VRC-resistant $(20 \%)$.

(ii). Echinocandins. All three echinocandins exhibited very good activity against most Candida spp., including C. parapsilosis SC isolates (100\% susceptibility). Non-susceptible to AFG and MFG C. albicans, C. tropicalis, and C. krusei isolates remained below $2 \%$. Of note, echinocandin resistance was found in 3\% of C. glabrata SC isolates, whereof $70 \%$ demonstrated elevated MIC values for all echinocandins (AFG, CAS, and MFG MIC $0.5-1,0.5-2$, and $0.5 \mathrm{mg} / \mathrm{L}$, respectively) but not to azoles. These strains were isolated from ICU patients hospitalized in different and far from each other medical centres and were distributed equally through the years of the study period ( $0-3$ isolates annually; $p=0.80$ ) (Figure 4 ).

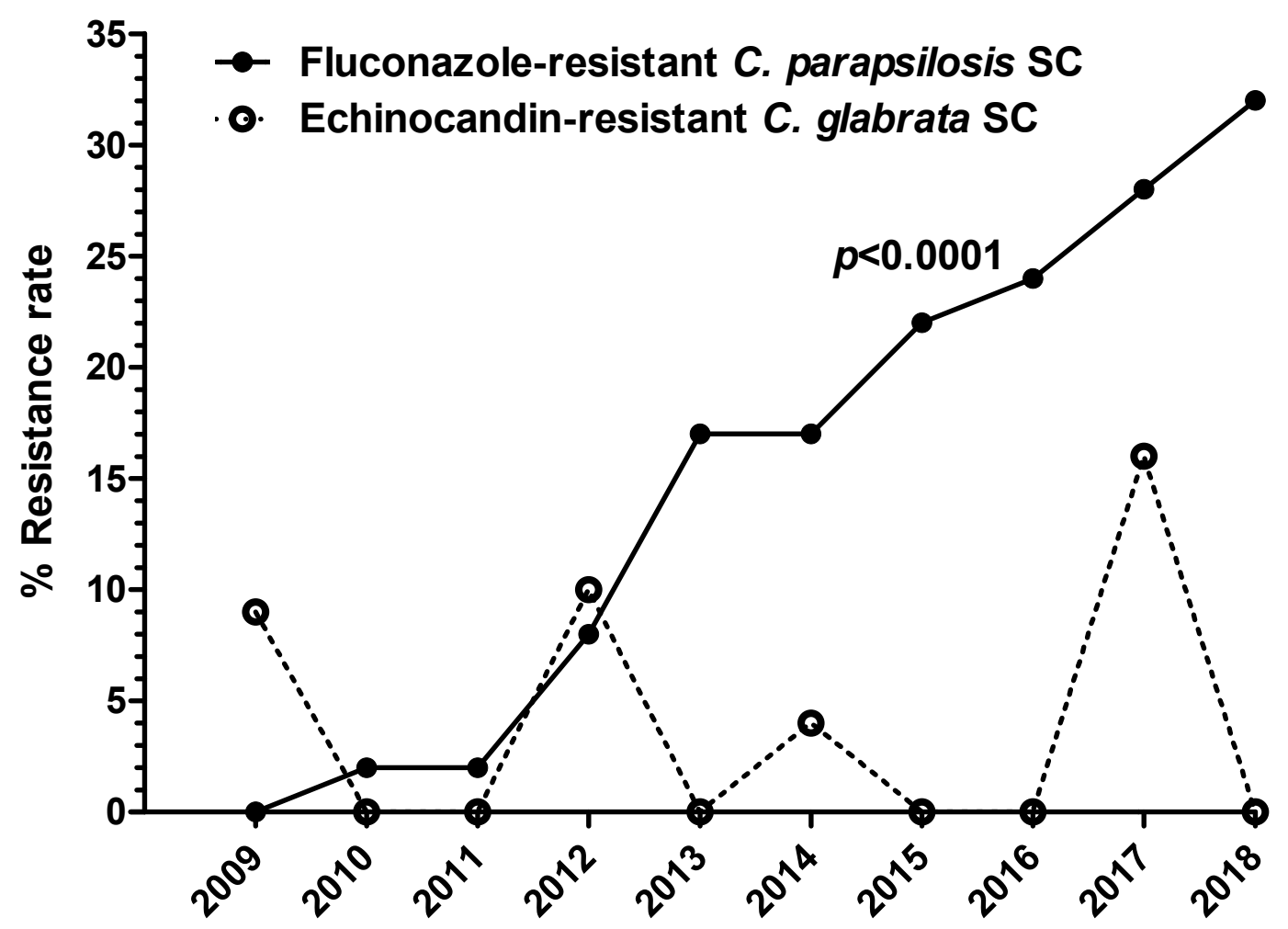

Figure 4. Trends of C. parapsilosis species complex (SC) to fluconazole resistance and of C. glabrata SC to echinocandin resistance. Statistically significant increase of fluconazole-resistant $C$. parapsilosis SC isolates was observed during the study period $(p<0.0001)$. 
No significant trend over time was found in the annual susceptibility rates of Candida spp. to the rest of the antifungals.

\section{Discussion}

In light of the constantly evolving epidemiological landscape of candidemia worldwide with important implications in this infection's management, continuous monitoring, specifically in previously under-investigated geographical areas, is warranted. Taking into account the existing literature, this is the first study aiming to determine the countrywide incidence of Candida BSIs in Greece, along with the sensitivity spectrum profiles of the etiological Candida spp. to antifungal agents. During the 10-year (2009-2018) period, a significant increase of the incidence of candidemia has been observed all over the country. During this period C. parapsilosis SC has emerged as a major causative agent of candidemia, now accounting for $41 \%$ of Candida bloodstream isolates. Worryingly, C. parapsilosis SC isolates have shown rising FLC resistance rate.

A precise estimate of the global burden of candidemia is difficult to assess since long-term surveillance data are limited and highly heterogeneous [1,27]. In fact, reported incidence rates vary significantly between countries, ranging from 2.0 to $21.0 / 100,000$ inhabitants [27], while differences may also occur within regions of the same country and between populations at risk $[28,29]$. Similar intracountry variations, attributed to differences in study periods, local practices, and antifungal drug use as well as distinct patient populations and degrees of illness severity have been recently described in a systematic review of the existing literature related to candidemia in Greece [9]. In a first attempt to depict the prevalence of serious fungal infections in this country, the incidence of Candida BSIs in ICU patients and in non-ICU immunosuppressed patients with haematological malignancies was estimated at 5.0/100,000 population (541 cases/year; 162 in ICU patients and 379 in non-ICU haematology patients) [30]. The present epidemiological survey of the Greek all cause patient population (all hospital units) is representative of the entire country over a 10-year period providing a more complete picture. The survey has revealed an average annual incidence of 5.56/100,000 inhabitants (639 cases/year; 284, 209, and 146 in IMWs, ICU, and SWs patients, respectively), which is in line with reports from Ireland (6.3) [31], Kuwait (5.29) [32], Mexico (5.0) [33], and Sweden (4.7) [34]. The incidence is lower than that reported in Thailand (13.3) [35], Hungary (11.0) [36], Denmark (8.13) [37], and Spain (8.1) [38], and higher than in Canada (2.91) [39], Australia (2.41) [40], Portugal (2.19) [41], and the Philippines (2.0) [42]. Of note, a recent epidemiological metaanalysis has shown that the overall pooled incidence rate of candidemia in Europe is $3.88 / 100,000$ inhabitants per year, yet is significantly higher in the southern (5.29) than in the northern (3.77) or the western (2.5) European countries [1], corroborating the present finding. Several factors may contribute to the high degree of variability in population-based candidemia incidences, such as geographical and ecological parameters, lack of uniformity in monitoring and reporting systems, the overall health of the studied patient populations, demographic development and setting of local health care systems, implementation of infection control procedures, stewardship programs and educational campaigns, as well as differences in clinical management and antimicrobial prescription policies $[1,2,43]$.

Of interest, the present findings have shown a significant increase in the incidence of candidemia. Namely the rates were $3.75,5.83$, and 7.01/100,000 inhabitants during the periods 2009 to 2011, 2012 to 2014, and 2015 to 2018, respectively ( $p=0.0002$ ). Notably, these findings are supported by other long-term, nationwide epidemiological surveillance studies of Candida BSIs in other European countries [44,45], highlighting the need for constant vigilance. A possible explanation for this rise is the growing number of patients at risk, taking into account that the European health care systems are called upon to provide services for an ever-increasing number of elderly and debilitated patients with complex and severe underlying disorders [46]. Prolonged hospital stay due to increased survival rates, expanding indications for treatment with immunosuppressive and antineoplastic drugs, increased number of solid organ and haematopoietic stem cell transplantation proce- 
dures, as well as extent use of indwelling medical devices, broad-spectrum antimicrobials, and parenteral nutrition, might also be considered as contributing factors [1]. Of note, Greece is particularly vulnerable to compound risks from discrepancies in the organization and resourcing of health care delivery practices, given that Greece, nowadays, like other Mediterranean countries, has medium-low-quality hospitals with a high occurrence of nosocomial infections [47]. Indeed, single-centre and regional studies from Italy have also reported similar increase in candidemia incidence over time [48,49]. This issue has experienced fluctuations since 2010, which may be explained by the unstable economic situation in Greece, due to the financial crisis which could have adversely influenced basic infection control measures and promoted the onset of hospital-acquired infections, like Candida BSIs as previously described [9]. In particular, during the study period, the number of Greek hospitals has been steadily decreased; in 2013 fell below 300, while in 2018 there were 271 hospitals all over the country, which is the lowest number in this study time interval. Correspondingly, the number of specialized hospital staff increased from 2000 to 2009, but it has been declining ever since [50]. At the same time, the number of patients hospitalized in public medical institutions was constantly increasing, resulting in an inadequate patient-to-nurse ratio, whereas there was deficiency of resources for medical care and training, as well as infection control programs accompanied by critical challenges in clinical management in regard to both the diagnosis (slow laboratory turnaround times, nonavailability of biomarkers) and treatment (specifically shortage of some antifungal agents) [51,52]. In fact, the increase in the incidence of candidemia reported in the present study coincided with the beginning (2012 to 2014) and the peak (2015 to 2018) of the financial crisis in Greece. Hence, it is apparent that severe socioeconomic events may influence the epidemiology of infectious diseases and lead to changes of the hospital settings that eventually will have deleterious impacts on human lives, bearing in mind that 29 patients die only in Europe from candidaemia every day [1].

Concurrently, a progressive rise of BSI attributed to NAC spp. has been recorded, consistent with the current local $[9,53]$ and global epidemiological trends $[1,2,7]$. In particular, the overall ratio of NAC spp. versus C. albicans was $1.7(p<0.0001)$. The present data have illustrated that this disproportion was mainly due to the considerable prevalence of $C$. parapsilosis SC in all medical units during the last years, given that the frequency of C. albicans isolation decreased from 2009 to 2018 (48\% to 31\%) in parallel with a doubling of C. parapsilosis SC recovery $(28 \%$ to $49 \%$; $p<0.0001)$. The proportion of other NAC spp. such as C. glabrata SC and C. tropicalis, that increased in several North American [54] as well as Central/North European [37,44] and East/Southeast Asian countries [2,55], remained stable. Overall, C. parapsilosis SC was the predominant species (41\%), followed by C. albicans $(37 \%)$, C. glabrata SC (10\%), C. tropicalis (7\%), C. krusei (1\%), and other rare Candida spp. (4\%). Emerging species, such as $C$. auris, had not been detected. Therefore, during the study period, Greece had not yet been incorporated in the increasingly expanding map of countries where C. auris BSIs had been documented [8]. Taking into account the published literature, this is the first study describing the epidemiological shift in favour of C. parapsilosis SC as the main etiologic agent of candidemia in the Greek all cause patient population [9]. This shift has lately been evident in local scale. Namely, the most recent single-centre studies in all cause patient population of Athens (capital of Greece; 2009-2018) and Patras (southwestern Greece; 2009-2017) revealed that $C$. parapsilosis SC were almost equally distributed with C. albicans-driven BSIs ( $37 \%$ versus $41 \%$ and $37 \%$ versus $40 \%$, respectively) $[9,53]$. Likewise, C. parapsilosis SC has outranked C. albicans in several geographical regions, such as South Africa [56] and South America (Brazil, Colombia, Peru) [57-59], or has comparable isolation rates [7] indicating that the incidence of this pathogen is continuously rising with consequent clinical importance.

The dominance of C. parapsilosis SC is worrisome since it has been associated with central venous catheter infections and the administration of parenteral nutrition due to its propensity to form tenacious biofilms, thus threatening ICU patients and newborns. In the present study, almost half (48\%) of both the adult ICU and neonatal/paediatric 
patients were infected with C. parapsilosis SC isolates, aligning with other surveys [60,61]. Of note, a recent multicentre study on antifungal prescription in Greek hospitals showed that the use of echinocandins was significantly higher in ICUs as compared with those in all other departments [62]. It can be assumed that in some medical units FLC was used as prophylaxis and on that account critically ill patients hospitalized in ICUs were considered as eligible subjects to be treated with an echinocandin in case of suspected breakthrough fungal infection. In addition, the rising incidence of FLC-resistant $C$. parapsilosis SC isolates in Greek hospitals might explain the extensive use of echinocandins as pre-emptive or empirical treatment in the ICU setting $[9,53]$. Thus, the increasing selection pressure mediated by a larger use of echinocandins probably promoted this local epidemiological shift considering that the increased use of echinocandins has been correlated with an expansion of $C$. parapsilosis SC $[9,48,63,64]$. Furthermore, a higher proportional increase of C. parapsilosis SC isolation rate was recorded in wards. This rising burden may be related to changes in the hospital case mix with an expanding population of immunosuppressed and/or debilitated patients [46] in conjunction with moderate compliance with infection control prevention guidelines and basic measures, such as hand hygiene, in debt-stricken Greek hospitals [51,52]. Hence, in contrast to C. albicans-driven candidemia that is acquired mostly endogenously [65], the horizontal transmission potential of C. parapsilosis SC via contaminated medical equipment and hands of health care personnel, which may lead to crossover infections between patients and is often responsible for nosocomial cluster outbreaks, cannot be excluded. Intensity of the shift towards C. parapsilosis SC is of concern, given that it may provide a challenge for current antifungal treatment strategies and stresses the need for species identification and susceptibility testing as well as thorough consideration of the local epidemiology.

Species-specific profiles may be used in an attempt to predict antifungal susceptibility, while awaiting susceptibility testing results [6]. Hence, accurate identification of the species implicated in candidemia is a crucial requisite for timely and optimally targeted antifungal treatment that in turn ensures better prognosis [4,5]. In recent years, matrix-assisted laser desorption-time-of-light mass spectrophotometry (MALDI-TOF MS) has emerged as a promising method for yeast identification. Nevertheless, this study evaluated 10-year retrospective epidemiological data, when MALDI-TOF MS was not broadly available [66]. Regarding the Greek hospital reality during the study period, identification of Candida isolates was made mainly with automated systems, while there was no capacity for performing molecular identification in laboratory routine [67]. Despite the fact that isolates belonging to different SCs can be reliably differentiated by assimilation methods, cryptic species within larger complexes exhibiting differences both in virulence and in the spectrum of antifungal resistance [68-70] may be missed. Although this can be considered as a limitation of the present study, it is partially offset by the low isolation rate of such species [68-70].

Since most of Candida spp. have undistinguishable colony morphologies on standard media that may not allow reliable differentiation, the routine use of chromogenic agars can increase significantly the detection rates of mixed species [71,72]. The incidence of MC may vary from $1.5 \%$ to $18.5 \%[9,32,71,73,74]$. In this study, MC occurred in $3 \%$ of episodes, with C. albicans being the most frequently isolated in combination with other Candida spp., consistent with the rates and distribution reported in previous multicentre studies conducted worldwide [32,75-78]. Nevertheless, only 4/28 (14\%) of the participating hospitals used chromogenic media, thus the incidence of MC might have been underestimated. Indeed, the proportion of MC cases in the present survey was slightly lower than a recent study carried out in a Greek tertiary care academic hospital during the same period, which detected a rate of $4.7 \%$ [9]. It is noteworthy that detection of MC remains crucial for optimum treatment, since species with intrinsic resistance or reduced susceptibility to different antifungals may be among the causative pathogens, as previously described [71]. In fact, 4/24 (17\%) MCs in the present study were caused by a common (2 C. albicans, 2 C. parapsilosis SC) and a rare Canidida spp. (2 C. kefyr, 1 C. lusitaniae, 1 C. sake), 
limiting therapeutic options [54]; FLC-susceptible-dose dependent/resistant C. parapsilosis SC were isolated from $3 / 24(12 \%)$ patients presented with C. albicans-C. parapsilosis SC coinfection; and 1/24 (4\%) MC was caused by C. albicans-C. krusei, with the latter having an inherent instinct of resistance to FLC, indicating the importance of using chromogenic media to detect MCs. Hence, special attention is required for isolating mixed Candida spp., particularly in immunocompromised patients.

The overuse of ineffective or unnecessary antifungal therapy is a prime mover for the emergence of resistance in Candida spp. Of note, the expanding incidence of Candida BSIs due to azole- and echinocandin-resistant isolates is considered a serious public health threat [79]. Despite the concern for a genetic predisposition to nonsusceptibility to echinocandins, several surveys have revealed that azole resistance occurs more commonly in C. parapsilosis SC $[80,81]$. Indeed, while resistance to echinocandins among C. parapsilosis SC isolates was not observed, in line with recent global antifungal surveillance results [82], the rate of FLC resistance was $20 \%$. A short time ago, FLC resistance was considered to be uncommon among $C$. parapsilosis SC strains. While the phenomenon had appeared to be restricted to certain geographic regions, an ever-growing number of FLC-resistant clinical isolates have been reported worldwide from Brazil [57,83,84], France [85], India [86], Korea [87,88], Kuwait [32], North America [82], and South Africa [56,89], whilst the problem is already broadly disseminated in Italy [48,82,90] and Turkey [91-93]. FLC resistance C. parapsilosis SC has been well associated with selective drug pressure attributable to the extensive use of FLC as prophylaxis and treatment or even to exposure to systemic antimicrobials $[94,95]$ with subsequent patient-to-patient spread in an epidemic way with clonal transmission and establishment of persistent resistant isolates within the hospital environment $[83-85,92]$. In the present study, FLC-resistant $C$. parapsilosis SC strains were found in all medical units of hospitals geographically distributed all over the country. Of note, in light of concerns about decreased susceptibility of $C$. parapsilosis SC to echinocandins, both the American [6] and the European [96] guidelines have recommended the use of FLC coupled with prompt catheter removal in patients with C. parapsilosis SC BSIs. At the same time, FLC is still the most intensely prescribed antifungal agent in the Greek hospitals [97]; considering its lower price compared with echinocandins, usually its administration may be preferable for C. parapsilosis SC-driven candidemias under European guidelines [96], while the overuse of antimicrobials in Greece is threatening [97]. These factors may be associated with the high rate of FLC-resistant C. parapsilosis SC bloodstream isolates reported in the present study. Worryingly, a significant increase in their incidence rate was identified over time (from $0 \%$ in 2009 to $32 \%$ in 2018, $p<0.0001$ ), as previously described [74,87], whereas FLC-VRC cross-resistance occurred in a high proportion of such isolates, being consistent with previous findings $[54,74,85,92,98]$. Notably, a trend of higher mortality rates in candidemic patients infected with FLC-resistant C. parapsilosis SC than in those with FLC-susceptible ( $42-50 \%$ versus $16-26 \%$, respectively) has been described [87,92]. Therefore, it is highly important to diligently monitor the local burden of antifungal resistance, which can undermine the clinical efficacy of commonly used antifungals and may have detrimental consequences that can potentially result in longer hospital stay, higher costs, and poor outcome.

On the other hand, echinocandins are considered to be the first-line treatment of C. glabrata SC-driven BSIs, since this particular species generally presents reduced susceptibility to azoles. Nevertheless, $C$. glabrata SC rapidly acquires resistance to echinocandins after repeated or long-term exposure to this antifungal class $[99,100]$. The present data are comparable with several population-based studies demonstrating 3-5\% echinocandin resistance among C. glabrata SC isolates [101]. The fact that all strains exhibiting cross-resistance to all three echinocandins, but not to azoles, were recovered from ICU patients, might be explained by the extensive use of echinocandins in the Greek ICU settings [62]. However, one should keep in mind that many centres worldwide have reported resistance rates of $10-15 \%$ [102,103], while echinocandin resistance in C. glabrata SC is related to clinical failure [103]. This underscores the need for implementation of local guidelines, as recently 
suggested [104], in the context that empirical antifungal strategies should be tailored to the nosocomial setting, highlighting once again the central role of epidemiological surveillance to avoid the development of resistant isolates.

Resistance to antifungal drugs poses a tremendous challenge in the treatment of invasive fungal infections. Despite a long history of clinical use, resistance to polyenes remains low [105]. Indeed, our data indicated a high rate (100\%) of in vitro susceptibility to amphotericin B (AMB) across all Candida spp. As a class, polyenes have an extended antifungal spectrum that covers most clinically relevant yeasts and moulds. Although conventional $\mathrm{AMB}$ deoxycholate has been associated with substantial toxicities, its lipid derivatives, particularly liposomal AMB, have an improved safety profile. Liposomal $\mathrm{AMB}(3 \mathrm{mg} / \mathrm{kg} /$ day) has been shown to be as effective as micafungin for treatment of Candida BSIs [106] and its use should be considered when there is a history of intolerance to echinocandins and/or azoles, the infection is refractory to other therapy, or the causative isolate is resistant to other agents [6]. Thus, adapting the current guidelines to local ecology described by increased levels of FLC and/or echinocandin resistance in certain settings, liposomal AMB may play a key role in the empirical treatment of candidemia at local scale.

Limitations of the present study comprise potential differences in clinical and laboratory practices across the participating hospitals as well as the lack of detailed individual patient data (demographics, comorbidities, previous antifungal drug exposure, risk factors for candidemia, outcome) given its retrospective nature. Nevertheless, the study fills a gap in the existing literature and provides a large contemporary overview on Candida BSIs from an entire country over a 10-year period, which can be instrumental in designing local therapeutic strategies and provide a point of reference paving the way for subsequent epidemiological surveys.

\section{Conclusions}

The present study provides a much-needed updated view of the epidemiology of candidemia in the Greek general patient population at national level since 2009. The incidence of candidemia increased significantly during the last decade and a species shift toward C. parapsilosis SC was observed. Although antifungal resistance levels remain relatively low in the total sample, the increase of FLC-resistant $C$. parapsilosis SC raises concern, pointing out the desirability of systematic susceptibility testing of all Candida bloodstream isolates so as to monitor and detect significant changes in trends. Overall, clinical recommendations must be balanced by epidemiological concerns. The present findings underscore the need for increased awareness, introduction of antifungal stewardship programmes, and strict implementation of infection control measures to diminish the incidence and resistance rates of Candida BSIs seen to be rising in Greece.

Author Contributions: Conception and design, V.M. and G.V.; data collection, all authors; data analysis and interpretation, V.M., M.S., S.C. and G.V.; writing-original draft preparation, V.M, M.S., G.S. and G.V.; writing-review and editing, all authors. All authors have read and agreed to the published version of the manuscript.

Funding: Under the auspice of the Hellenic Society of Medical Mycology. This project was funded and supported by Gilead Sciences Hellas.

Institutional Review Board Statement: The study protocol was approved by the local institutional Review Board and Bioethics Committee of each participating hospital.

Informed Consent Statement: Written patient consent was not required due to the observational nature of the study.

Data Availability Statement: Data available on request.

Conflicts of Interest: The authors declare no conflict of interest.

\section{Appendix A}

Investigators of the Candi-Candi Network (in alphabetical order): 
Baka Vasiliki; Department of Microbiology, Korgialenio Benakio Hellenic Red Cross Hospital, Athens, Greece

Baka Stavroula; Department of Microbiology, "Aretaieion" General Hospital, National and Kapodistrian University of Athens, Athens, Greece

Biniari Theodora; Department of Microbiology, "Agioi Anargyroi" General Oncology Hospital, Athens, Greece

Charalampaki Nikoletta; Department of Microbiology, Thriassio General Hospital, Attika, Greece

Chatzimoschou Athanasios; Laboratory of Infectious Diseases, 3rd Department of Pediatrics, Aristotle University School of Health Sciences, Hippokration General Hospital, Thessaloniki, Greece

Christidou Athanasia; Department of Microbiology, University Hospital of Heraklion, Crete, Greece

Christofidou Myrto; Department of Microbiology, University Hospital of Patras, Patras, Greece

Chronopoulou Genovefa; Department of Microbiology, Euroclinic Hospital, Athens, Greece

Deliolanis Ioannis; Department of Microbiology, Laikon General Hospital, Athens, Greece Dendrinos Ioannis; Department of Microbiology, Metropolitan Hospital, Piraeus, Greece

Drogari-Apiranthitou Maria; 4th Department of Internal Medicine, "Attikon” University General Hospital, National and Kapodistrian University of Athens, Athens, Greece

Ganteris George; Department of Microbiology, "G. Gennimatas” General Hospital, Athens, Greece

Gartzonika Konstantina; Department of Microbiology, University Hospital of Ioannina, Ioannina, Greece

Giannopoulou Panagiota; Department of Microbiology, Thriassio General Hospital, Attika, Greece

Glynou Eirini; Department of Microbiology, "Elena Venizelou” Maternity Hospital, Athens, Greece

Kafkoula Helen; Department of Microbiology, Korgialenio Benakio Hellenic Red Cross Hospital, Athens, Greece

Karachalios Stefanos; Department of Microbiology, "Agioi Anargyroi" General Oncology Hospital, Athens, Greece

Karapsias Stergios; Clinical Department of Microbiology, 251 Air Force General Hospital, Athens, Greece

Karle Paraskevi; Department of Microbiology, General Hospital of Nikaia "Agios Panteleimon", Piraeus, Greece

Katsiaflaka Anna; Department of Microbiology, General Hospital of Larissa, Larissa, Greece

Koiliari Helen; Department of Microbiology, KAT General Hospital, Athens, Greece

Lamprou Eleni; Department of Microbiology, "Metaxa" Anticancer Hospital, Piraeus, Greece

Mantzana Paraskevi; Department of Microbiology, AHEPA University Hospital, Aristotle University of Thessaloniki, Thessaloniki, Greece

Maraki Sofia; Department of Microbiology, University Hospital of Heraklion, Crete, Greece

Markou Fani; Department of Microbiology, General Hospital of Serres, Serres, Greece

Martsoukou Maria; Department of Microbiology, Sismanogleio General Hospital, Athens, Greece

Meletiadis Joseph; Clinical Microbiology Laboratory, "Attikon" University General Hospital, Medical School, National and Kapodistrian University of Athens, Athens, Greece Michailidou Chrysi; Department of Microbiology, Hippokration General Hospital, Thessaloniki Greece 
Mpakosi Alexandra; Department of Microbiology, General Hospital of Nikaia "Agios Panteleimon", Piraeus, Greece

Nepka Martha; Department of Microbiology, Evaggelismos General Hospital, Athens, Greece

Orfanidou Maria; Department of Microbiology, "G. Gennimatas" General Hospital, Athens, Greece

Pana Zoi Dorothea; 3rd Department of Paediatrics, Infectious Diseases Unit, Aristotle University School of Medicine, Hippokration General Hospital, Thessaloniki, Greece

Panopoulou Maria; Laboratory of Microbiology, School of Medicine, Democritus University of Thrace, Alexandroupolis, Greece

Pantazatou Angeliki; Department of Microbiology, Laikon General Hospital, Athens, Greece

Panteli Kalliopi; Department of Microbiology, Asklepieion Voulas General Hospital, Attika, Greece

Papaemmanouil Virginia; Department of Microbiology, "Metaxa” Anticancer Hospital, Piraeus, Greece

Papaioannou Vasiliki; Department of Microbiology, KAT General Hospital, Athens, Greece

Perivolioti Efstathia; Department of Microbiology, Evaggelismos General Hospital, Athens, Greece

Platsouka Evangelia; Department of Microbiology, Konstantopouleio, Patission General Hospital, Athens, Greece

Poulou Aggeliki; Department of Microbiology, General Hospital of Serres, Serres, Greece

Pournaras Spyros; Clinical Microbiology Laboratory, "Attikon" University General Hospital, Medical School, National and Kapodistrian University of Athens, Athens, Greece

Priavali Efthalia; Department of Microbiology, University Hospital of Ioannina, Ioannina, Greece

Roilides Emmanuel; 3rd Department of Paediatrics, Infectious Diseases Unit, Aristotle University School of Medicine, Hippokration General Hospital, Thessaloniki, Greece

Sereti Christina; Department of Microbiology, Thriassio General Hospital, Attika, Greece

Skandami Vasiliki; Department of Microbiology, Hippokration Athens General Hospital, Athens, Greece

Skarmoutsou Nikoletta; Department of Microbiology, Sismanogleio General Hospital, Athens, Greece

Skiada Anna; 1st Department of Medicine, Laiko Hospital, School of Medicine, National and Kapodistrian University of Athens, Athens, Greece

Skoura Lemonia; Department of Microbiology, AHEPA University Hospital, Aristotle University of Thessaloniki, Thessaloniki, Greece

Spiliopoulou Anastasia; Department of Microbiology, University Hospital of Patras, Patras, Greece

Themeli-Digalaki Katerina; Department of Microbiology, Tzaneio General Hospital, Piraeus, Greece

Tsakalos Anastasios; Department of Microbiology, “G. Gennimatas” General Hospital, Athens, Greece

Tsiplakou Sophia; Department of Microbiology, KAT General Hospital, Athens, Greece

Tsiriga Athanasia; Department of Microbiology, Hippokration Athens General Hospital, Athens, Greece

Vagdatli Helen; Department of Microbiology, Hippokration General Hospital, Thessaloniki Greece

Vagiakou Helen; Department of Microbiology, "G. Gennimatas" General Hospital, Athens, Greece

Vasilaki Olga; Department of Microbiology, AHEPA University Hospital, Aristotle University of Thessaloniki, Thessaloniki, Greece 
Vossou Christina; Department of Microbiology, Euroclinic Hospital, Athens, Greece Voulgaridi Ioanna; Department of Microbiology, General Hospital of Larissa, Larissa, Greece

Zarkotou Olympia; Department of Microbiology, Tzaneio General Hospital, Piraeus, Greece

\section{References}

1. Koehler, P.; Stecher, M.; Cornely, O.A.; Koehler, D.; Vehreschild, M.J.G.T.; Bohlius, J.; Wisplinghoff, H.; Vehreschild, J.J. Morbidity and mortality of candidaemia in Europe: An epidemiologic meta-analysis. Clin. Microbiol. Infect. 2019, 25, 1200-1212. [CrossRef] [PubMed]

2. Lamoth, F.; Lockhart, S.; Berkow, E.; Calandra, T. Changes in the epidemiological landscape of invasive candidiasis. J. Antimicrob. Chemother. 2018, 73, i4-i13. [CrossRef] [PubMed]

3. Nor Ain Wan Ismail, W.; Jasmi, N.; Mehmood Khan, T.; Hoi Hong, Y.; Fen Neoh, C. Systematic Literature Review The Economic Burden of Candidemia and Invasive Candidiasis: A Systematic Review. Value Health Reg. Issues 2020, 21, 53-58. [CrossRef] [PubMed]

4. Garnacho-Montero, J.; Díaz-Martín, A.; García-Cabrera, E.; de Pipaón, M.R.P.; Hernández-Caballero, C.; Lepe-Jimánez, J.A. Impact on hospital mortality of catheter removal and adequate antifungal therapy in Candida spp. bloodstream infections. J. Antimicrob. Chemother. 2013, 68, 206-213. [CrossRef] [PubMed]

5. Ostrosky-Zeichner, L.; Kullberg, B.J.; Bow, E.J.; Hadley, S.; León, C.; Nucci, M.; Patterson, T.F.; Perfect, J.R. Early treatment of candidemia in adults: A review. Med. Mycol. 2011, 49, 113-120. [CrossRef] [PubMed]

6. Pappas, P.G.; Kauffman, C.A.; Andes, D.R.; Clancy, C.J.; Marr, K.A.; Ostrosky-Zeichner, L.; Reboli, A.C.; Schuster, M.G.; Vazquez, J.A.; Walsh, T.J.; et al. Clinical Practice Guideline for the Management of Candidiasis: 2016 Update by the Infectious Diseases Society of America. Clin. Infect. Dis. 2015, 62, e1-e50. [CrossRef]

7. Tóth, R.; Nosek, J.; Mora-Montes, H.M.; Gabaldon, T.; Bliss, J.M.; Nosanchuk, J.D.; Turner, S.A.; Butler, G.; Vágvölgyi, C.; Gácser, A. Candida parapsilosis: From Genes to the Bedside. Clin. Microbiol. Rev. 2019, 32, e00111-18. [CrossRef]

8. Rhodes, J.; Fisher, M.C. Global epidemiology of emerging Candida auris. Curr. Opin. Microbiol. 2019, 52, 84-89. [CrossRef]

9. Siopi, M.; Tarpatzi, A.; Kalogeropoulou, E.; Damianidou, S.; Vasilakopoulou, A.; Vourli, S.; Pournaras, S.; Meletiadis, J. Epidemiological trends of fungemia in Greece with a focus on candidemia during the recent financial crisis: A 10-year survey in a tertiary care academic hospital and review of literature. Antimicrob. Agents Chemother. 2020, 64, e01516-19. [CrossRef]

10. Ministry of Health: Supervised Bodies and Legal Entities. Available online: https://www.moh.gov.gr/articles/ministry/ organogramma/129-foreis(webpage in Greek); (accessed on 25 October 2021).

11. Bassetti, M.; Giacobbe, D.R.; Vena, A.; Trucchi, C.; Ansaldi, F.; Antonelli, M.; Adamkova, V.; Alicino, C.; Almyroudi, M.P.; Atchade, E.; et al. Incidence and outcome of invasive candidiasis in intensive care units (ICUs) in Europe: Results of the EUCANDICU project. Crit. Care 2019, 23. [CrossRef]

12. Arendrup, M.C.; Meletiadis, J.; Mouton, J.W.; Lagrou, K.; Hamal, P.; Guinea, J. Subcommittee on Antifungal Susceptibility Testing (AFST) of the ESCMID European Committee for Antimicrobial Susceptibility Testing (EUCAST) Method for the Determination of Broth Dilution Minimum Inhibitory Concntrations of Antifungal Agents for Yeasts. EUCAST E.DEF 7.3.1. 2017. Available online: http:/ / www.eucast.org (accessed on 25 September 2021).

13. The European Committee on Antimicrobial Susceptibility Testing. Overview of Antifungal ECOFFs and Clinical Breakpoints for Yeasts, Moulds and Dermatophytes Using the EUCAST E.Def 7.3, E.Def 9.3 and E.Def 11.0 Procedures. Version 2. 2020. Available online: http:/ / www.eucast.org (accessed on 25 September 2021).

14. Pfaller, M.A.; Diekema, D.J.; Procop, G.W.; Wiederhold, N.P. Multicenter Evaluation of the New Vitek 2 Yeast Susceptibility Test Using New CLSI Clinical Breakpoints for Fluconazole. J. Clin. Microbiol. 2014, 52, 2126. [CrossRef] [PubMed]

15. Astvad, K.M.; Perlin, D.S.; Johansen, H.K.; Jensen, R.H.; Arendrup, M.C. Evaluation of Caspofungin Susceptibility Testing by the New Vitek 2 AST-YS06 Yeast Card Using a Unique Collection of FKS Wild-Type and Hot Spot Mutant Isolates, Including the Five Most Common Candida Species. Antimicrob. Agents Chemother. 2013, 57, 177. [CrossRef] [PubMed]

16. Cuenca-Estrella, M.; Gomez-Lopez, A.; Alastruey-Izquierdo, A.; Bernal-Martinez, L.; Cuesta, I.; Buitrago, M.J.; Rodriguez-Tudela, J.L. Comparison of the Vitek 2 antifungal susceptibility system with the clinical and laboratory standards institute (CLSI) and European Committee on Antimicrobial Susceptibility Testing (EUCAST) Broth Microdilution Reference Methods and with the Sensititre YeastOne and Etest techniques for in vitro detection of antifungal resistance in yeast isolates. J. Clin. Microbiol. 2010, 48, 1782-1786. [CrossRef] [PubMed]

17. Dannaoui, E.; Espinel-Ingroff, A. Antifungal Susceptibly Testing by Concentration Gradient Strip Etest Method for Fungal Isolates: A Review. J. Fungi 2019, 5, 108. [CrossRef]

18. Eschenauer, G.A.; Nguyen, M.H.; Shoham, S.; Vazquez, J.a.; Morris, A.J.; Pasculle, W.a.; Kubin, C.J.; Klinker, K.P.; Carver, P.L.; Hanson, K.E.; et al. Real-world experience with echinocandin MICs against Candida species in a multicenter study of hospitals that routinely perform susceptibility testing of bloodstream isolates. Antimicrob. Agents Chemother. 2014, 58, 1897-1906. [CrossRef]

19. CLSI. Performance Standards for Antifungal Susceptibility Testing of Yeasts, 1st ed.; Clinical and Laboratory Standards Institute: Wayne, PA, USA, 2017. 
20. CLSI. Epidemiological Cutoff Values for Antifungal Susceptibility Testing, 2nd ed.; Clinical and Laboratory Standards Institute: Wayne, PA, USA, 2018.

21. Salsé, M.; Gangneux, J.-P.; Cassaing, S.; Delhaes, L.; Fekkar, A.; Dupont, D.; Botterel, F.; Costa, D.; Bourgeois, N.; Bouteille, B.; et al. Multicentre study to determine the Etest epidemiological cut-off values of antifungal drugs in Candida spp. and Aspergillus fumigatus species complex. Clin. Microbiol. Infect. 2019, 25, 1546-1552. [CrossRef]

22. Espinel-Ingroff, A.; Turnidge, J.; Alastruey-Izquierdo, A.; Botterel, F.; Canton, E.; Castro, C.; Chen, Y.C.; Chen, Y.; Chryssanthou, E.; Dannaoui, E.; et al. Method-dependent epidemiological cutoff values for detection of triazole resistance in Candida and Aspergillus species for the Sensititre Yeastone colorimetric broth and etest agar diffusion methods. Antimicrob. Agents Chemother. 2019, 63, e01651-18. [CrossRef]

23. Espinel-Ingroff, A.; Arendrup, M.; Canton, E.; Cordob, S.; Dannaoui, E.; Garcia-Rodriguez, J.; Gonzalez, G.M.; Govender, N.P.; Martin-Mazuelos, E.; Lackner, M.; et al. Multicenter study of method-dependent epidemiological cutoff values for detection of resistance in candida spp. and aspergillus spp. to amphotericin B and echinocandins for the etest agar diffusion method. Antimicrob. Agents Chemother. 2017, 61, 1792-1808. [CrossRef]

24. Espinel-Ingroff, A.; Alvarez-Fernandez, M.; Cantón, E.; Carver, P.L.; Chen, S.C.-A.; Eschenauer, G.; Getsinger, D.L.; Gonzalez, G.M.; Govender, N.P.; Grancini, A.; et al. Multicenter study of epidemiological cutoff values and detection of resistance in Candida spp. to anidulafungin, caspofungin, and micafungin using the Sensititre YeastOne colorimetric method. Antimicrob. Agents Chemother 2015, 59, 6725-6732. [CrossRef]

25. Cantón, E.; Pemán, J.; Hervás, D.; Iñiguez, C.; Navarro, D.; Echeverría, J.; Martínez-Alarcón, J.; Fontanals, D.; Gomila-Sard, B.; Buendía, B.; et al. Comparison of three statistical methods for establishing tentative wild-type population and epidemiological cutoff values for echinocandins, amphotericin B, flucytosine, and six Candida species as determined by the colorimetric Sensititre YeastOne method. J. Clin. Microbiol. 2012, 50, 3921-3926. [CrossRef]

26. Population Estimates and Projections I DataBank. Available online: https://databank.worldbank.org/source/populationestimates-and-projections\# (accessed on 25 September 2021).

27. Bongomin, F.; Gago, S.; Oladele, R.O.; Denning, D.W. Global and Multi-National Prevalence of Fungal Diseases-Estimate Precision. J. Fungi 2017, 3, 57. [CrossRef] [PubMed]

28. Chakrabarti, A.; Sood, P.; Rudramurthy, S.M.; Chen, S.; Kaur, H.; Capoor, M.; Chhina, D.; Rao, R.; Eshwara, V.K.; Xess, I.; et al. Incidence, characteristics and outcome of ICU-acquired candidemia in India. Intensive Care Med. 2014, 41, 285-295. [CrossRef] [PubMed]

29. Bassetti, M.; Merelli, M.; Righi, E.; Diaz-Martin, A.; Rosello, E.M.; Luzzati, R.; Parra, A.; Trecarichi, E.M.; Sanguinetti, M.; Posteraro, B.; et al. Epidemiology, Species Distribution, Antifungal Susceptibility, and Outcome of Candidemia across Five Sites in Italy and Spain. J. Clin. Microbiol. 2013, 51, 4167-4172. [CrossRef] [PubMed]

30. Gamaletsou, M.N.; Drogari-Apiranthitou, M.; Denning, D.W.; Sipsas, N.V. An estimate of the burden of serious fungal diseases in Greece. Eur. J. Clin. Microbiol. Infect. Dis. 2016, 35, 1115-1120. [CrossRef]

31. Dorgan, E.; Denning, D.W.; McMullan, R. Burden of fungal disease in Ireland. J. Med. Microbiol. 2015, 64, 423-426. [CrossRef]

32. Alobaid, K.; Ahmad, S.; Asadzadeh, M.; Mokaddas, E.; Al-Sweih, N.; Albenwan, K.; Alfouzan, W.; Al-Obaid, I.; Jeragh, A.; Al-Roomi, E.; et al. Epidemiology of Candidemia in Kuwait: A Nationwide, Population-Based Study. J. Fungi 2021, 7, 673. [CrossRef]

33. Corzo-León, D.E.; Armstrong-James, D.; Denning, D.W. Burden of serious fungal infections in Mexico. Mycoses 2015, 58 (Suppl 5), 34-44. [CrossRef]

34. Özenci, V.; Klingspor, L.; Ullberg, M.; Chryssanthou, E.; Denning, D.W.; Kondori, N. Estimated burden of fungal infections in Sweden. Mycoses 2019, 62, 1043-1048. [CrossRef]

35. Chayakulkeeree, M.; Denning, D.W. Serious fungal infections in Thailand. Eur. J. Clin. Microbiol. Infect. Dis. 2017, 36, 931-935. [CrossRef]

36. Sinkó, J.; Sulyok, M.; Denning, D.W. Burden of serious fungal diseases in Hungary. Mycoses 2015, 58 (Suppl 5), 29-33. [CrossRef]

37. Risum, M.; Astvad, K.; Johansen, H.K.; Schønheyder, H.C.; Rosenvinge, F.; Knudsen, J.D.; Hare, R.K.; Datcu, R.; Røder, B.L.; Antsupova, V.S.; et al. Update 2016-2018 of the Nationwide Danish Fungaemia Surveillance Study: Epidemiologic Changes in a 15-Year Perspective. J. Fungi 2021, 7, 491. [CrossRef] [PubMed]

38. Rodriguez-Tudela, J.L.; Alastruey-Izquierdo, A.; Gago, S.; Cuenca-Estrella, M.; León, C.; Miro, J.M.; Nuñez Boluda, A.; Ruiz Camps, I.; Sole, A.; Denning, D.W. Burden of serious fungal infections in Spain. Clin. Microbiol. Infect. 2015, 21, 183-189. [CrossRef] [PubMed]

39. Dufresne, S.F.; Cole, D.C.; Denning, D.W.; Sheppard, D.C. Serious fungal infections in Canada. Eur. J. Clin. Microbiol. Infect. Dis. 2017, 36, 987-992. [CrossRef] [PubMed]

40. Chapman, B.; Slavin, M.; Marriott, D.; Halliday, C.; Kidd, S.; Arthur, I.; Bak, N.; Heath, C.H.; Kennedy, K.; Morrissey, C.O.; et al. Changing epidemiology of candidaemia in Australia. J. Antimicrob. Chemother. 2017, 72, 1103-1108. [CrossRef] [PubMed]

41. Sabino, R.; Verissímo, C.; Brandão, J.; Martins, C.; Alves, D.; Pais, C.; Denning, D.W. Serious fungal infections in Portugal. Eur. J. Clin. Microbiol. Infect. Dis. 2017, 36, 1345-1352. [CrossRef] [PubMed]

42. Batac, M.C.R.; Denning, D. Serious fungal infections in the Philippines. Eur. J. Clin. Microbiol. Infect. Dis. 2017, 36, 937-941. [CrossRef] [PubMed] 
43. Pfaller, M.A.; Castanheira, M. Nosocomial Candidiasis: Antifungal Stewardship and the Importance of Rapid Diagnosis. Med. Mycol. 2016, 54, 1-22. [CrossRef]

44. Adam, K.-M.; Osthoff, M.; Lamoth, F.; Conen, A.; Erard, V.; Boggian, K.; Schreiber, P.W.; Zimmerli, S.; Bochud, P.-Y.; Neofytos, D.; et al. Trends of the Epidemiology of Candidemia in Switzerland: A 15-Year FUNGINOS Survey. Open Forum Infect. Dis. 2021, 8, ofab471. [CrossRef]

45. Hesstvedt, L.; Gaustad, P.; Andersen, C.T.; Haarr, E.; Hannula, R.; Haukland, H.H.; Hermansen, N.-O.; Larssen, K.W.; Mylvaganam, H.; Ranheim, T.E.; et al. Twenty-two years of candidaemia surveillance: results from a Norwegian national study. Clin. Microbiol. Infect. 2015, 21, 938-945. [CrossRef]

46. OECD/European Union Health at a Glance: Europe 2020: State of Health in the EU Cycle. Available online: https:/ / ec.europa. eu/health/sites/default/files/state/docs/2020_healthatglance_rep_en.pdf (accessed on 23 October 2021).

47. Björnberg, A. Euro Health Consumer Index 2017. PharmacoEcon. Outcomes News 2018, 796, 31.

48. Mesini, A.; Mikulska, M.; Giacobbe, D.R.; Del Puente, F.; Gandolfo, N.; Codda, G.; Orsi, A.; Tassinari, F.; Beltramini, S.; Marchese, A.; et al. Changing epidemiology of candidaemia: Increase in fluconazole-resistant Candida parapsilosis. Mycoses 2020, 63, 361-368. [CrossRef] [PubMed]

49. Prigitano, A.; Cavanna, C.; Passera, M.; Ossi, C.; Sala, E.; Lombardi, G.; Grancini, A.; De Luca, C.; Bramati, S.; Gelmi, M.; et al. CAND-LO 2014-15 study: Changing epidemiology of candidemia in Lombardy (Italy). Infection 2016, 44, 765-780. [CrossRef] [PubMed]

50. Hospitals in Greece 2000-2018 I Statista. Available online: https:/ /www.statista.com/statistics/557023/hospitals-in-greece/ (accessed on 23 October 2021).

51. Karanikolos, M.; Heino, P.; McKee, M.; Stuckler, D.; Legido-Quigley, H. Effects of the global financial crisis on health in high-income OECD countries: A narrative review. Int. J. Health Serv. 2016, 46, 208-240. [CrossRef] [PubMed]

52. Economou, C.; Kaitelidou, D.; Kentikelenis, A.; Sissouras, A.; Maresso, A. The impact of the financial crisis on the health system and health in Greece. In In Economic Crisis, Health Systems and Health in Europe: Country Experience; Maresso, A., Mladovsky, P., Thomson, S., Sagan, A., Karanikolos, M., Richardson, E., Cylus, J., Evetovits, T., Jowett, M., Figueras, J., et al., Eds.; Observatory Studies Series, No. 41. European Observatory on Health Systems and Policies: Copenhagen, Denmark, 2015.

53. Papadimitriou-Olivgeris, M.; Spiliopoulou, A.; Kolonitsiou, F.; Bartzavali, C.; Lambropoulou, A.; Xaplanteri, P.; Anastassiou, E.D.; Marangos, M.; Spiliopoulou, I.; Christofidou, M. Increasing incidence of candidaemia and shifting epidemiology in favor of Candida non-albicans in a 9-year period (2009-2017) in a university Greek hospital. Infection 2018, 47, 209-216. [CrossRef] [PubMed]

54. Pfaller, M.A.; Diekema, D.J.; Turnidge, J.D.; Castanheira, M.; Jones, R.N. Twenty Years of the SENTRY Antifungal Surveillance Program: Results for Candida Species From 1997-2016. Open Forum Infect. Dis. 2019, 6, S79-S94. [CrossRef] [PubMed]

55. Ngamchokwathana, C.; Chongtrakool, P.; Waesamaae, A.; Chayakulkeeree, M. Risk Factors and Outcomes of Non- albicans Candida Bloodstream Infection in Patients with Candidemia at Siriraj Hospital-Thailand's Largest National Tertiary Referral Hospital. J. Fungi 2021, 7, 269. [CrossRef] [PubMed]

56. Govender, N.P.; Patel, J.; Magobo, R.E.; Naicker, S.; Wadula, J.; Whitelaw, A.; Coovadia, Y.; Kularatne, R.; Govind, C.; Lockhart, S.R.; et al. Emergence of azole-resistant Candida parapsilosis causing bloodstream infection: results from laboratorybased sentinel surveillance in South Africa. J. Antimicrob. Chemother. 2016, 71, 1994-2004. [CrossRef]

57. Rodrigues, D.K.B.; Bonfietti, L.X.; Garcia, R.A.; Araujo, M.R.; Rodrigues, J.S.; Gimenes, V.M.F.; Melhem, M.S.C. Antifungal susceptibility profile of Candida clinical isolates from 22 hospitals of São Paulo State, Brazil. Braz. J. Med. Biol. Res. Rev. Bras. Pesqui. Med. Biol. 2021, 54, e10928. [CrossRef]

58. Bustamante, B.; Martins, M.A.; Bonfietti, L.X.; Szeszs, M.W.; Jacobs, J.; Garcia, C.; Melhem, M.S.C. Species distribution and antifungal susceptibility profile of Candida isolates from bloodstream infections in Lima, Peru. J. Med. Microbiol. 2014, 63, 855-860. [CrossRef]

59. Nucci, M.; Queiroz-Telles, F.; Alvarado-Matute, T.; Tiraboschi, I.N.; Cortes, J.; Zurita, J.; Guzman-Blanco, M.; Santolaya, M.E.; Thompson, L.; Sifuentes-Osornio, J.; et al. Epidemiology of candidemia in Latin America: a laboratory-based survey. PLoS ONE 2013, 8, e59373. [CrossRef]

60. Arsić Arsenijević, V.; Otašević, S.; Janić, D.; Minić, P.; Matijašević, J.; Medić, D.; Savić, I.; Delić, S.; Nestorović Laban, S.; Vasiljević, Z.; et al. Candida bloodstream infections in Serbia: First multicentre report of a national prospective observational survey in intensive care units. Mycoses 2018, 61, 70-78. [CrossRef] [PubMed]

61. Chan, S.; Baley, E.D.; Hossain, J.; Di Pentima, M.C. Candida species bloodstream infections in hospitalised children: A 10-year experience. J. Paediatr. Child Health 2015, 51, 857-861. [CrossRef] [PubMed]

62. Papadimitriou-Olivgeris, M.; Andrianaki, A.M.; Marangos, M.; Sipsas, N.; Apostolidi, E.A.; Maltezos, E.; Panagopoulos, P.; Karapiperis, D.; Arvaniti, K.; Perdikouri, E.-I.; et al. Hospital-wide antifungal prescription in Greek hospitals: a multicenter repeated point-prevalence study. Eur. J. Clin. Microbiol. Infect. Dis. 2019, 39, 243-248. [CrossRef] [PubMed]

63. Bailly, S.; Maubon, D.; Fournier, P.; Pelloux, H.; Schwebel, C.; Chapuis, C.; Foroni, L.; Cornet, M.; Timsit, J.-F. Impact of antifungal prescription on relative distribution and susceptibility of Candida spp.-Trends over 10 years. J. Infect. 2016, 72, 103-111. [CrossRef]

64. Forrest, G.N.; Weekes, E.; Johnson, J.K. Increasing incidence of Candida parapsilosis candidemia with caspofungin usage. J. Infect. 2008, 56, 126-129. [CrossRef] 
65. Mayer, F.L.; Wilson, D.; Hube, B. Candida albicans pathogenicity mechanisms. Virulence 2013, 4, 119-128. [CrossRef]

66. Lau, A. Matrix-Assisted Laser Desorption Ionization Time-of-Flight for Fungal Identification. Clin. Lab. Med. 2021, 41, 267-283. [CrossRef]

67. Sipsas, N.V.; Pagoni, M.N.; Kofteridis, D.P.; Meletiadis, J.; Vrioni, G.; Papaioannou, M.; Antoniadou, A.; Petrikkos, G.; Samonis, G. Management of Invasive Fungal Infections in Adult Patients with Hematological Malignancies in Greece during the Financial Crisis: Challenges and Recommendations. J. Fungi 2018, 4, 94. [CrossRef]

68. Brilhante, R.S.N.; Sales, J.A.; da Silva, M.L.Q.; de Oliveira, J.S.; Pereira, L.A.; Pereira-Neto, W.A.; Cordeiro, R.A.; Sidrim, J.J.C.; Castelo-Branco, D.S.C.M.; Rocha, M.F.G. Antifungal susceptibility and virulence of Candida parapsilosis species complex: an overview of their pathogenic potential. J. Med. Microbiol. 2018, 67, 903-914. [CrossRef]

69. Hou, X.; Xiao, M.; Chen, S.C.-A.; Wang, H.; Yu, S.-Y.; Fan, X.; Kong, F.; Xu, Y.-C. Identification and Antifungal Susceptibility Profiles of Candida nivariensis and Candida bracarensis in a Multi-Center Chinese Collection of Yeasts. Front. Microbiol. 2017, 8, 5. [CrossRef]

70. Borman, A.M.; Szekely, A.; Linton, C.J.; Palmer, M.D.; Brown, P.; Johnson, E.M. Epidemiology, antifungal susceptibility, and pathogenicity of Candida africana isolates from the United Kingdom. J. Clin. Microbiol. 2013, 51, 967-972. [CrossRef] [PubMed]

71. Gülmez, D.; Alp, S.; Gursoy, G.; Ayaz, C.M.; Dogan, O.; Arikan-Akdagli, S.; Akova, M. Mixed fungaemia: an 18-year report from a tertiary-care university hospital and a systematic review. Clin. Microbiol. Infect. 2020, 26, 833-841. [CrossRef] [PubMed]

72. Jensen, J.; Muñoz, P.; Guinea, J.; Rodríguez-Créixems, M.; Peláez, T.; Bouza, E. Mixed fungemia: Incidence, risk factors, and mortality in a general hospital. Clin. Infect. Dis. 2007, 44, e109-14. [CrossRef] [PubMed]

73. Díaz-García, J.; Mesquida, A.; Sánchez-Carrillo, C.; Reigadas, E.; Muñoz, P.; Escribano, P.; Guinea, J. Monitoring the Epidemiology and Antifungal Resistance of Yeasts Causing Fungemia in a Tertiary Care Hospital in Madrid, Spain: Any Relevant Changes in the Last 13 Years? Antimicrob. Agents Chemother. 2021, 65, e01827-20. [CrossRef] [PubMed]

74. Mete, B.; Zerdali, E.Y.; Aygun, G.; Saltoglu, N.; Balkan, I.I.; Karaali, R.; Kaya, S.Y.; Karaismailoglu, B.; Kaya, A.; Urkmez, S.; et al. Change in species distribution and antifungal susceptibility of candidemias in an intensive care unit of a university hospital (10-year experience). Eur. J. Clin. Microbiol. Infect. Dis. 2020, 40, 325-333. [CrossRef] [PubMed]

75. Lockhart, S.R.; Iqbal, N.; Cleveland, A.A.; Farley, M.M.; Harrison, L.H.; Bolden, C.B.; Baughman, W.; Stein, B.; Hollick, R.; Park, B.J.; et al. Species identification and antifungal susceptibility testing of Candida bloodstream isolates from population-based surveillance studies in two U.S. cities from 2008 to 2011. J. Clin. Microbiol. 2012, 50, 3435-3442. [CrossRef] [PubMed]

76. Lortholary, O.; Desnos-Ollivier, M.; Sitbon, K.; Fontanet, A.; Bretagne, S.; Dromer, F.; Bouges-Michel, C.; Poilane, I.; Dunan, J.; Galeazzi, G.; et al. Recent exposure to caspofungin or fluconazole influences the epidemiology of candidemia: A prospective multicenter study involving 2,441 patients. Antimicrob. Agents Chemother. 2011, 55, 532-538. [CrossRef]

77. Arendrup, M.C.; Bruun, B.; Christensen, J.J.; Fuursted, K.; Johansen, H.K.; Kjældgaard, P.; Knudsen, J.D.; Kristensen, L.; Møller, J.; Nielsen, L.; et al. National surveillance of fungemia in Denmark (2004 to 2009). J. Clin. Microbiol. 2011, 49, 325-334. [CrossRef]

78. Nguyen, M.H.; Peacock, J.E.; Morris, A.J.; Tanner, D.C.; Nguyen, M.L.; Snydman, D.R.; Wagener, M.M.; Rinaldi, M.G.; Yu, V.L. The changing face of candidemia: Emergence of non-Candida albicans species and antifungal resistance. Am. J. Med. 1996, 100, 617-623. [CrossRef]

79. Biggest Threats and Data / Antibiotic/Antimicrobial Resistance ICDC. Available online: https://www.cdc.gov/drugresistance/ biggest-threats.html?CDC_AA_refVal=https\%3A\%2F\%2Fwww.cdc.gov\%2Fdrugresistance\%2Fbiggest_threats.html\#candida (accessed on 28 October 2021).

80. Meletiadis, J.; Curfs-Breuker, I.; Meis, J.F.; Mouton, J.W. In Vitro Antifungal Susceptibility Testing of Candida Isolates with the EUCAST Methodology, a New Method for ECOFF Determination. Antimicrob. Agents Chemother. 2017, 61, e02372-16. [CrossRef]

81. Cantón, E.; Pemán, J.; Quindós, G.; Eraso, E.; Miranda-Zapico, I.; Álvarez, M.; Merino, P.; Campos-Herrero, I.; Marco, F.; de la Pedrosa, E.G.G.; et al. Prospective Multicenter Study of the Epidemiology, Molecular Identification, and Antifungal Susceptibility of Candida parapsilosis, Candida orthopsilosis, and Candida metapsilosis Isolated from Patients with Candidemia. Antimicrob. Agents Chemother. 2011, 55, 5590. [CrossRef] [PubMed]

82. Castanheira, M.; Deshpande, L.M.; Messer, S.A.; Rhomberg, P.R.; Pfaller, M.A. Analysis of global antifungal surveillance results reveals predominance of Erg11 Y132F alteration among azole-resistant Candida parapsilosis and Candida tropicalis and country-specific isolate dissemination. Int. J. Antimicrob. Agents 2020, 55, 105799. [CrossRef] [PubMed]

83. Thomaz, D.Y.; de Almeida, J.N.J.; Lima, G.M.E.; Nunes, M.d.O.; Camargo, C.H.; Grenfell, R.d.C.; Benard, G.; Del Negro, G.M.B. An Azole-Resistant Candida parapsilosis Outbreak: Clonal Persistence in the Intensive Care Unit of a Brazilian Teaching Hospital. Front. Microbiol. 2018, 9, 2997. [CrossRef] [PubMed]

84. Pinhati, H.M.S.; Casulari, L.A.; Souza, A.C.R.; Siqueira, R.A.; Damasceno, C.M.G.; Colombo, A.L. Outbreak of candidemia caused by fluconazole resistant Candida parapsilosis strains in an intensive care unit. BMC Infect. Dis. 2016, 16, 433. [CrossRef]

85. Fekkar, A.; Blaize, M.; Bouglé, A.; Normand, A.-C.; Raoelina, A.; Kornblum, D.; Kamus, L.; Piarroux, R.; Imbert, S. Hospital Outbreak of Fluconazole-Resistant Candida parapsilosis: Arguments for Clonal Transmission and Long-Term Persistence. Antimicrob. Agents Chemother. 2021, 65, e02036-20. [CrossRef]

86. Singh, A.; Singh, P.K.; de Groot, T.; Kumar, A.; Mathur, P.; Tarai, B.; Sachdeva, N.; Upadhyaya, G.; Sarma, S.; Meis, J.F.; et al. Emergence of clonal fluconazole-resistant Candida parapsilosis clinical isolates in a multicentre laboratory-based surveillance study in India. J. Antimicrob. Chemother. 2019, 74, 1260-1268. [CrossRef]

87. Kim, J.H.; Suh, J.W.; Kim, M.J. Epidemiological Trends of Candidemia and the Impact of Adherence to the Candidemia Guideline: Six-Year Single-Center Experience. J. Fungi 2021, 7, 275. [CrossRef] 
88. Choi, Y.J.; Kim, Y.-J.; Yong, D.; Byun, J.-H.; Kim, T.S.; Chang, Y.S.; Choi, M.J.; Byeon, S.A.; Won, E.J.; Kim, S.H.; et al. FluconazoleResistant Candida parapsilosis Bloodstream Isolates with Y132F Mutation in ERG11 Gene, South Korea. Emerg. Infect. Dis. 2018, 24, 1768-1770. [CrossRef]

89. Shuping, L.; Mpembe, R.; Mhlanga, M.; Naicker, S.D.; Maphanga, T.G.; Tsotetsi, E.; Wadula, J.; Velaphi, S.; Nakwa, F.; Chibabhai, V.; et al. Epidemiology of Culture-confirmed Candidemia among Hospitalized Children in South Africa, $2012-2017$. Pediatr. Infect. Dis. J. 2021, 40, 730-737. [CrossRef]

90. Martini, C.; Torelli, R.; Groot, T.d.; De Carolis, E.; Morandotti, G.A.; De Angelis, G.; Posteraro, B.; Meis, J.F.; Sanguinetti, M. Prevalence and Clonal Distribution of Azole-Resistant Candida parapsilosis Isolates Causing Bloodstream Infections in a Large Italian Hospital. Front. Cell. Infect. Microbiol. 2020, 10, 232. [CrossRef]

91. Demirci-Duarte, S.; Arikan-Akdagli, S.; Gülmez, D. Species distribution, azole resistance and related molecular mechanisms in invasive Candida parapsilosis complex isolates: Increase in fluconazole resistance in 21 years. Mycoses 2021, 64, 823-830. [CrossRef] [PubMed]

92. Arastehfar, A.; Hilmioğlu-Polat, S.; Daneshnia, F.; Pan, W.; Hafez, A.; Fang, W.; Liao, W.; Şahbudak-Bal, Z.; Metin, D.Y.; de Almeida Júnior, J.N.; et al. Clonal Candidemia Outbreak by Candida parapsilosis Carrying Y132F in Turkey: Evolution of a Persisting Challenge. Front. Cell. Infect. Microbiol. 2021, 22, 676177. [CrossRef] [PubMed]

93. Arikan-Akdagli, S.; Gülmez, D.; Doğan, Ö.; Çerikçioğlu, N.; Doluca Dereli, M.; Birinci, A.; Yıldıran, Ş.T.; Ener, B.; Öz, Y.; Metin, D.Y.; et al. First multicentre report of in vitro resistance rates in candidaemia isolates in Turkey. J. Glob. Antimicrob. Resist. 2019, 18, 230-234. [CrossRef] [PubMed]

94. Ben-Ami, R.; Olshtain-Pops, K.; Krieger, M.; Oren, I.; Bishara, J.; Dan, M.; Wiener-Well, Y.; Weinberger, M.; Zimhony, O.; Chowers, M.; et al. Antibiotic exposure as a risk factor for fluconazole-resistant Candida bloodstream infection. Antimicrob. Agents Chemother. 2012, 56, 2518-2523. [CrossRef] [PubMed]

95. Hebert, C.; Villaran, R.; Tolentino, J.; Best, L.; Boonlayangoor, S.; Pitrak, D.; Lin, M.; Weber, S.G. Prior antimicrobial exposure and the risk for bloodstream infection with fluconazole-non-susceptible Candida strains. Scand. J. Infect. Dis. 2010, 42, 506-509. [CrossRef]

96. Cornely, O.A.; Bassetti, M.; Calandra, T.; Garbino, J.; Kullberg, B.J.; Lortholary, O.; Meersseman, W.; Akova, M.; Arendrup, M.C.; Arikan-Akdagli, S.; et al. ESCMID* guideline for the diagnosis and management of Candida diseases 2012: Non-neutropenic adult patients. Clin. Microbiol. Infect. 2012, 18 (Suppl 7), 19-37. [CrossRef]

97. Country Overview of Antimicrobial Consumption: Greece. 2019. Available online: https://www.ecdc.europa.eu/en/ antimicrobial-consumption/database/country-overview (accessed on 28 October 2021).

98. Astvad, K.M.T.; Johansen, H.K.; Røder, B.L.; Rosenvinge, F.S.; Knudsen, J.D.; Lemming, L.; Schønheyder, H.C.; Hare, R.K.; Kristensen, L.; Nielsen, L.; et al. Update from a 12-Year Nationwide Fungemia Surveillance: Increasing Intrinsic and Acquired Resistance Causes Concern. J. Clin. Microbiol. 2018, 56, e01564-17. [CrossRef]

99. Healey, K.R.; Perlin, D.S. Fungal Resistance to Echinocandins and the MDR Phenomenon in Candida glabrata. J. Fungi 2018, 4, 105. [CrossRef]

100. Rivero-Menendez, O.; Navarro-Rodriguez, P.; Bernal-Martinez, L.; Martin-Cano, G.; Lopez-Perez, L.; Sanchez-Romero, I.; PerezAyala, A.; Capilla, J.; Zaragoza, O.; Alastruey-Izquierdo, A. Clinical and Laboratory Development of Echinocandin Resistance in Candida glabrata: Molecular Characterization. Front. Microbiol. 2019, 10, 1585. [CrossRef]

101. Perlin, D.S. Mechanisms of echinocandin antifungal drug resistance. Ann. N. Y. Acad. Sci. 2015, 1354, 1-11. [CrossRef]

102. Farmakiotis, D.; Tarrand, J.J.; Kontoyiannis, D.P. Drug-resistant Candida glabrata infection in cancer patients. Emerg. Infect. Dis. 2014, 20, 1833-1840. [CrossRef] [PubMed]

103. Alexander, B.D.; Johnson, M.D.; Pfeiffer, C.D.; Jiménez-Ortigosa, C.; Catania, J.; Booker, R.; Castanheira, M.; Messer, S.A.; Perlin, D.S.; Pfaller, M.A. Increasing Echinocandin Resistance in Candida glabrata: Clinical Failure Correlates With Presence of FKS Mutations and Elevated Minimum Inhibitory Concentrations. Clin. Infect. Dis. An Off. Publ. Infect. Dis. Soc. Am. 2013, 56, 1724-1732. [CrossRef] [PubMed]

104. Wang, Y.; McGuire, T.M.; Hollingworth, S.A.; Dong, Y.; Driel, M.L. Van Antifungal agents for invasive candidiasis in nonneutropenic critically ill adults: What do the guidelines recommend? Int. J. Infect. Dis. 2019, 89, 137-145. [CrossRef] [PubMed]

105. Klepser, M. The value of amphotericin B in the treatment of invasive fungal infections. J. Crit. Care 2011, 26, 225-e1. [CrossRef]

106. Kuse, E.R.; Chetchotisakd, P.; da Cunha, C.A.; Ruhnke, M.; Barrios, C.; Raghunadharao, D.; Sekhon, J.S.; Freire, A.; Ramasubramanian, V.; Demeyer, I.; et al. Micafungin versus liposomal amphotericin B for candidaemia and invasive candidosis: a phase III randomised double-blind trial. Lancet 2007, 369, 1519-1527. [CrossRef] 